\title{
Las cartas de Troilo y Briseida de Juan Rodríguez del Padrón en las Bienandanzas e fortunas de Lope García de Salazar*
}

\author{
Pilar SAquero SuÁreZ-SOMONTE \\ Universidad Complutense de Madrid \\ psaquero@filol.ucm.es
}

Recibido: 10 de mayo de 2012

Aceptado: 4 de junio de 2012

\section{RESUMEN}

Las cartas originales de Juan Rodríguez del Padrón fueron conocidas y utilizadas todavía en la segunda mitad del siglo XV. Prueba de esto la encontramos en la obra del autor vasco Lope García de Salazar, titulada Bienandanzas e fortunas, en la que se insertan dos de dichas cartas: la de Troilo a Briseida y la de Briseida a Troilo. En este trabajo se estudia la relación genealógica del ms. de las cartas utilizado por Salazar con el resto de la tradición manuscrita, cuyas lecturas son cotejadas con el texto de las cartas de las Bienandanzas, reproducido según el ms. de la Real Biblioteca de la Historia (ms. 9-10-2/2100 RAH). Palabras clave: Juan Rodríguez del Padrón. Cartas originales. Lope García de Salazar. Bienandanzas e fortunas.

Saquero SuÁrez-Somonte, P., «Las cartas de Troilo y Briseida de Juan Rodríguez del Padrón en las Bienandanzas e fortunas de Lope García de Salazar», Cuad. Fil. Clás. Estud. Lat. 32.1 (2012) 145-171.

\section{The letters of Troilo and Briseida by Juan Rodríguez del Padrón in Lope García de Salazar's Bienandanzas e fortunas}

\begin{abstract}
The original letters of Juan Rodríguez del Padrón were know and utilized as early the second half of the fifteenth century. We find proof of this in the work of Basque author Lope García de Salazar titled Bienandanzas e fortunas, which includes two of the letters: one from Troilo to Briseida and another from Briseida to Troilo. The paper aims to analyze the genealogical relationship of the manuscript of de letters used by Salazar with the rest of the manuscript tradition whose readings are collated with the text of the Bienandanzas reproduced from de Royal Library of History (ms. 9-10-2/2100 RAH).

Keywords: Juan Rodríguez del Padrón. Original letters. Lope García de Salazar. Bienandanzas e fortunas. Saquero SuÁreZ-Somonte, P., «The letters of Troilo and Briseida by Juan Rodríguez del Padrón in Lope García de Salazar's Bienandanzas e fortunas», Cuad. Fil. Clás. Estud. Lat. 32.1 (2012) 145-171.
\end{abstract}

\footnotetext{
* Este trabajo se enmarca en el Proyecto FFI2011-23805, financiado por el Ministerio de Ciencia e Innovación (ahora Ministerio de Economía y Competitividad). 
Las Bienandanzas e fortunas, obra del escritor vasco Lope García de Salazar, es sin duda la muestra más clara de que el Bursario de Juan Rodríguez del Padrón, o más concretamente, dos de sus cartas originales, fueron conocidas y utilizadas todavía en la segunda mitad del siglo XV.

La obra que nos permite hacer esta afirmación comienza con un sustancioso Pró$\log 0^{1}$, en el que su autor se nos presenta explicando las razones y causas por las que tomó la pluma para llevarla a cabo:

E porque yo Lope García de Salazar, fijo de Ochoa de Salazar e de doña Teresa de Muñatones, su muger, oviendo mucho a voluntad de saber e de oir de los tales fechos desde mi mocedad fasta aquí, me trabajé de aver los libros e estorias de los fechos del mundo faziéndolos buscar por las provincias e casas de los reyes e príncipes cristianos de allende la mar e de aquende por mis despensas con mercaderes e mareantes, e por mi mesmo a esta parte. E a plazer de Nuestro Señor alcançé de todos ellos lo que obe en memoria, por lo qual de todos ellos e de la memoria de los antepasados, e de las oídas e vistas mías, e obrando sobre mia fortuna estando en la mi casa de Sant Martín de los que yo engendré e crié e acrecenté, e temeroso del mal bevedizo e desafuziado de la esperança de los que son cautivos en tierra de moros que esperan salir por redención de sus bienes e por limosnas de buenas gentes, e yo temiéndome de la desordenada codiçia, que es por levar mis bienes como los ya veía levar que no me soltarían.

Esperando la misericordia de Dios e por quitar pensamiento e imaginaçión conponí este libro e escribílo de mi mano, e començélo en el mes de julio del año del Señor de mil a quatroçientos e setenta e un años. E por que en él se fallaran muchas bien andanças e acreçentamientos d'estados que los prínçipes e gentes menudas de las quatro generaçiones que son gentiles e judíos e cristianos, obieron en que ellos bisquieron en honra e a su plazer. Otrosí, ovo muchos dellos que con fortunas decayeron e feneçieron sus vidas miserablemente en mucho dolor, en trabaxo e angustia. Otrosí, porque yo la fize e escribí aconpañándome la dicha fortuna, su nonbre derecho deve ser livro de las Bienandanças e Fortunas que fizo Lope Garçía de Salazar començaré en cómo Dios crió el mundo.......De las menguas que en este libro se fallaren o de palabras mal puestas, no sea dada la culpa a mí fasta saber si es en el herror de los trasladadores segund suele acaescer, e si por este libro qu'es escrito de mi mano e enmendado en muchos logares, qu'es de setecientas fojas e demas de dos el pliego menor, que estará en la iglesia de Sant Martín, donde si plaze a Nuestro Señor será mi sepultura, con todos los otros mis libros, fallarán las dichas mencoas, sea dada la culpa a la mi nigligençia e non a la mi voluntad, porque me entremetí a fablar en tantos e tan altos fechos, aunque Dios sabe que lo fize por la dicha mi nescesidad. E además d'ella porque aquellos que non podiendo aber tantos libros como aquí se faze mençión, por este libro fallen memoria de todos estos fechos. Otrosí, por las que yo fallé por memoria e por vista, e nunca fueran ecritas, escrevílas aquí por que non quedasen olvidadas por sienpre....... Otrosí, porque sepan dar razón en estos fechos quando necesario les fuere, faré apartamiento de todas las cosas prinçipales de los prínçipes e probincias e cibudades e caballeros e casas e linajes e omeçidas de linajes e muertes, con sus capítulos en veinte e cinco libros con sus tablas en cada uno sobre sí de letra colorada.

\footnotetext{
${ }^{1}$ Lope García de Salazar, Las bienandanzas e fortunas. Códice del siglo XV. Primera impresión del texto completo, con prólogo, notas e índices por Angel Rodríguez Herrero. Introducción por el Excmo. Sr. Marqués de Arriluce de Ybarra, vol. I, Bilbao 1967: 8-17 [esp. 12 ss.]. Sobre la fiabilidad de esta edición volveremos más adelante.
} 
Nos encontamos con un curiosísimo personaje, Lope García de Salazar, nacido en Vizcaya (en la Casa-Torre de San Martín de Muñatones, en el concejo de San Julián de Musques del valle de Somorrostro), en 1399, que a pesar de dedicar buena parte de su vida al ejercicio profesional de las armas, supo conjugarlo, desde su juventud, con su afición bibliófila, lectora y observadora, que se refleja en dos importantes libros, a saber: Crónica de Siete Casas de Vizcaya y Castilla, realizada en 1454, y el Libro de las bienandanzas y fortunas, que, como nos dice en el prólogo, fue comenzado en 1471 y probablemente terminado poco antes de su muerte, en 1476.

Esta última obra fue redactada cuando estaba preso y encerrado en su Casa-Torre de San Martín por dos de sus hijos, Juan Salazar "El Moro" y Pedro de Salazar. La razón de esta disputa familiar se debe al hecho de que Lope García de Salazar había obtenido en 1451 del rey Juan II de Castilla, a quien había servido en todos los casos de guerra, además de remuneración económica la autorización de fundar Mayorazgo, y Lope García de Salazar lo hizo a favor de Lope de Salazar, segundo de sus hijos ${ }^{2}$, y no del primogénito, Ochoa de Salazar. Pero estos dos hijos mayores murieron algunos años después, primero Lope en 1462, y luego Ochoa en 1467, lo que determinó a la mujer de Lope García de Salazar, doña Juana de Butrón y Múgica, a revocar en 1469 la disposición del Mayorazgo en favor ahora de su hijo Juan de Salazar "El Moro".

Es este Juan y su hermano Pedro de Salazar los que cercaron y prendieron a su padre para obligarle a que otorgase al primero el mayorazgo, lo que terminó por hacer el 19 de diciembre de 1471, disposición confirmada por Enrique IV por privilegio de 9 de enero de 1472.

La violencia desencadenada por los dos hijos, que ocasionó la muerte de su padre, fue denunciada penalmente por un hijo de Lope de Salazar, Ochoa de Salazar, nieto del autor, quien precisamente ordenó en 1492 a Cristóbal de Mieres que hiciese copia del original, testimonio éste el más antiguo, tras la desaparición de aquél, que se conoce del Libro de las bienandanzas y fortunas, y que actualmente se encuentra en la Biblioteca de la Real Academia de la Historia (Ms. 9- 10- 2/ 2100 RAH).

Así pues, partiendo de lo que desde la juventud, como él mismo nos dice, había leído, oído y visto, Lope García de Salazar como consuelo de su triste situación y para que los que no posean tantos libros como él ha recopilado puedan conocer los principales hechos históricos acaecidos desde el comienzo de la creación del mundo hasta el momento en que escribe, elabora una Crónica o Historia Universal (Villacorta 2005,pp.5-58), en 25 libros, los dos primeros dedicados al Antiguo Testamento, los seis siguientes (3-8) a la Antigüedad Clásica; el 9, 10 y 11 se ocupan de los reinos de Francia e Inglaterra, el 12 de las guerras en Tierra Santa, desde el 13 al 19 de la Península Ibérica y los seis últimos, del origen y sucesión de los señores de Vizcaya.

Como señala A. Rodríguez Herrero (1967, pp.8-17), Lope García de Salazar «llegó a reunir notable biblioteca que unido a su genio observador de las cosas de su tiempo y al trato con los doctos de su época vino a poseer un arsenal de noticias de

\footnotetext{
${ }^{2}$ De su matrimonio con Juana de Butrón y Múgica, Lope García de Salazar tuvo seis hijos y tres hijas, a saber: Ochoa, Lope, Gonzalo, Fernando, Juan, Pedro, Teresa, Mayor y Juana.
} 
gran valor para conocer la vida social de la Edad Media, período tan interesante en la Historia de España».

En efecto, en los últimos veinte años, especialmente después de un importante libro del medievalista Harvey L. Sharrer (1979), se ha abordado la obra de Salazar teniendo muy en cuenta las abundantes fuentes por él utilizadas y que en muchos casos pueden representar versiones hoy desaparecidas de algunas obras o testimonios que proceden de ramificaciones de la tradición manuscrita desconocidas hasta el momento, o que pueden poner en tela de juicio la datación sancionada de alguna obra, como es, por ejemplo, el caso del texto de viajes titulado Libro del Infante don Pedro de Portugal, cuya fecha de composición fue establecida por su máximo conocedor Francis M. Rogers ${ }^{3}$ a comienzos del siglo XVI, pero que ha de retrasarse entre cincuenta y setenta años porque Salazar conoce y cita pasajes de este curioso libro de viajes, como muy bien ha demostrado Harvey L. Sharrer (1977, pp.85-98; 1997, pp.205-212).

En cuanto a la utilización de las fuentes, Lope García de Salazar nos advierte hacia el final del citado Prólogo que de las carencias o faltas ('menguas') o de las palabras mal puestas que en el libro se hallaren no se le culpe a él hasta saber «si es en el herror de los trasladadores segund suele acaescer e si por este libro qu'es escrito de mi mano e enmendado en muchos logares, qu'es de setecientas fojas e de mas de dos el pliego menor.»

Aunque su libro alcanzó una dimensión bastante grande, dado el espacio de tiempo abarcado y el volumen de las fuentes recopiladas, tuvo necesariamente que abreviarlas y es así como operó, pero facilitando en general al lector referencias bibliográficas por si pudiese y quisiese acceder al texto entero del libro o libros que él resumía. Como bien ha indicado Gemma Avenoza (2003, pp.5-37), para los primeros libros de las Bienandanzas, Lope García de Salazar «transcribe, abrevia, extracta, reproduce pero no se aparta demasiado de la letra de su original, al menos mientras su fuente es la Biblia, cuyo texto respeta en extremo, pero cuando lo abandona actúa con mayor libertad, resumiendo y extractando los libros que maneja.»

Podríamos decir con Federico Bravo (2000, pp.303-327) que Lope García de Salazar practica lo que se llamaría 'cultura del zapping', en la que se privilegia el fragmento como principio estructural frente a modelos lineales y orgánicos de construcción textual.

En efecto, en los libros 3 y 4 dedicados a la materia de Troya, nuestro autor inserta en el cuerpo del texto cuatro epístolas en castellano que proceden de las correspondientes Heroidas de Ovidio, a saber: la quinta (Enone a Paris), la sexta (Hipsípila a Jasón), la novena (Deyanira a Hércules) y la duodécima (Medea a Jasón). Todas ellas habían sido traducidas por los redactores alfonsíes e insertadas en la General Estoria, de donde pasaron a Las Sumas de la historia troyana, y de donde sin duda las tomó Lope García de Salazar. Ahora bien, las tres últimas coinciden exactamente

\footnotetext{
${ }^{3}$ Cf. Gómez de Santiesteban, Libro del Infante don Pedro de Portugal, Lisboa, Fundaçao Calouste Gulbenkian, 1962; del mismo filólogo es el completísimo estudio The Travels of the Infante Dom Pedro de Portugal, Cambridge, Mass.: Harvard Univ. Press, 1961.
} 
con el texto que nos ofrece Las Sumas de la historia troyana, mientras que la primera (Enone a Paris) es exactamente la misma que encontramos en la General Estoria.

Este hecho ha permitido a Harvey L. Sharrer (1979, p. 13) formular la hipótesis de que Salazar se sirvió de un manuscrito de Las Sumas, distinto de los dos que se conocen en la actualidad.

Además, en el libro cuarto Salazar ha insertado, como en su momento señaló Ana María Marín Sánchez (1995, pp. 193-211), dos de las cartas originales de Juan Rodríguez del Padrón, a saber: la de Troilo a Briseida y la de ésta a Troilo. Partiendo del supuesto de que no es tarea fácil determinar de qué manuscrito se sirvió Salazar para su versión en las Bienandanzas, la citada filóloga, teniendo presente la mayoría de los testimonios de estas dos cartas salvo el del manuscrito de Palermo, aborda, por un lado, la relación que media entre todos ellos y, por otro, el estudio más pormenorizado de las lecciones singulares del texto de las Bienandanzas.

Aunque sin entrar a fondo en la cuestión de la relación genealógica de la tradición manuscrita, con buen criterio y creemos que con bastante acierto, sostiene lo siguiente (1995, p.200):

A la vista de estos datos parace lícito concluir que existió un arquetipo que se bifurcaría en dos ramas, de una de las cuales descendería $\mathbf{M}$ y de la otra un subarquetipo $(\boldsymbol{\beta})$, donde ya estaría al menos la omisión arriba señalada, pero que aún guardaría bastante parecido con M. Muy próximo a él debería encontrarse el manuscrito utilizado por Salazar. También a $\boldsymbol{\beta}$ remitirían en última instancia los restantes testimonios.

Por otra parte, dice Marín Sánchez:

si la carencia del original de las Buenandanzas hace difícil decidir en cada momento a quién deben imputarse los cambios operados en su versión de estas cartas respecto a los otros manuscritos, por la misma razón, la no conservación del arquetipo de dichas cartas no permite afirmar con plena seguridad en qué momento de la transmisión se han producido las diferentes lecturas que entre ellos se documentan ni cuál de las dos ramas se halla más próxima al arquetipo. Este es el motivo por el que, salvo claras excepciones, son tenidas en cuenta las lecciones singulares de la versión de las Buenandanzas. De otro modo, tendríamos que enfrentarnos a toda una gama de posibilidades que, en la mayoría de los casos, deberíamos dejar sin resolver.

De acuerdo con estas palabras, Marín Sánchez dedica la mayor parte de su buen trabajo al estudio de dichas lecciones singulares. Por nuestra parte, en la nueva edición del Bursario recientemente publicada, hemos dedicado un amplio espacio (Saquero-González Rolán 2010, pp.52-67) al estudio de las tres cartas originales de Juan Rodríguez del Padrón, donde, sobre la base de los manuscritos M (= Biblioteca Nacional de Madrid, ms. 6.052), F (= Bibliothèque National de Paris, Manuscrits espagnols, $\left.n^{\circ} 586\right), \mathbf{G}$ (= Bibliothèque National de Paris, Manuscrits espagnols, $\mathrm{n}^{\circ} 590$ ), I (= Bibliothèque National de Paris, Manuscrits espagnols, $n^{\circ} 313$ ); B (= Ginebra, Fundation Bodmer, ms. Cod. 45) y S (= Palermo, San Martino delle Scale, ms. II- B11), todos ellos del siglo XV, pudimos establecer, en primer lugar, que $\mathbf{M}$ es el más completo de todos ellos, por transmitirnos además de las dos cartas de Troilo a Bri- 
seida y de Briseida a Troilo, la de Madreselva a Mauseol, que falta en IFGBS, y que, además de M, sólo se encuentra en el ms. Add. 33. 382 de la British Library; en segundo lugar, que IFGBS remontan a un arquetipo común a todos ellos (le dimos la sigla $\mathbf{X}$ ), que es independiente de $\mathbf{M}$. En la mayoría de los casos su texto es inferior al de $\mathbf{M}$, aunque en otros, pocos y contados, lo superan. Además, dentro del grupo formado por IFGBS, se pueden distinguir dos familias: una formada por IS y otra por FG, cuyo modelo estaba emparentado con $\mathbf{B}$.

Por lo que se refiere al manuscrito en el que se basó Salazar para las dos cartas citadas en su Libro de las bienandanzas e fortunas $(=\mathbf{S a})$, solamente podrá ser definido tras una colación exhaustiva con el conjunto de la tradición manuscrita, es decir con MIFGBS.

Así pues, hemos procedido a transcribir el texto de las dos cartas de acuerdo con el códice de Mieres (ms. 9- 10- 2/2100) de la Real Academia de la Historia, que sirvió de base a la edición paleográfica de Ángel Rodríguez Herrero, pero que, como han señalado distintos estudiosos, entre ellos Harvey L. Sharrer (1977, pp. 85-98), es más útil por haber incluido una reproducción fotográfica del manuscrito que por el acierto en la transcripción ${ }^{4}$.

En efecto, además de confundir el signo de la $z$ con la s (rasón en vez de razón), en el breve espacio de estas dos cartas ofrece otros muchos errores, algunos de cierta importancia como 'costreñiia' en vez de 'costreñir e' (211, 1. 31), 'mandó' en vez de 'marido' $(215,1.24)$, 'Oponelgi' en vez 'Opon el gigante' $(217,1.26)$, 'delinante' en vez de 'declinante' $(217,1.4)$, 'quita' en vez 'de que tu' $(218,1.26)$, 'solfantes' en vez de 'soflantes' $(219,1.36)$, 'en la gamas' en vez de 'en lagrimas' $(219,1.25)$, 'pospesar' en vez de 'prosperar' $(220,1.3)$, etc., etc.

Una vez transcrito el texto de Salazar, hemos procedido a cotejar todas y cada una de sus lecturas con las que nos ofrecen el resto de los manuscritos (= MIFGBS), poniendo como lema, independientemente de su bondad o corrección, la lección de Sa e inmediatamente las de los demás testimonios. Podemos así establecer los siguientes hechos:

1) En Sa falta (¿por pérdida de un folio?, ¿por eliminación consciente de Salazar?, ¿por la culpa del copista Cristobal de Mieres?) un muy amplio trozo de texto que corresponde al relato que hace Briseida de un sueño en el que se ve cercada en una gran roca: «E aún más te digo que la noche passada, que truxo el día de la décima cuarta batalla, me viera cercada en una grand roca donde alojava un emperador e una semblante emperatriz y grandes compañas de príncipes, reyes, damas y cavalleros y gentiles hombres, que a mi parecer andavan todos vestidos de guerra, e pensando refrescar de las armas que dexado avían por se dar al reposo, he aquí donde viene en sitio d'ellos un cava-

\footnotetext{
${ }^{4}$ Además del acceso directo al manuscrito de Mieres, que nos facilita la edición de Rodríguez Herrero, disponemos en la red de una transcripción más correcta realizada como Tesis de Licenciatura por Ana Ma Marín Sánchez: Lope García de Salazar. Istoria de las bienandanzas e fortunas (http:// parnaseo.uv.es/ Lemir/ Textos/ bienandanzas/ Menu.htm/).
} 
1lero, su yelmo enlazado de todas pieças en punto, e dos antiguas dueñas con él: la una le dava la lança y la otra le servía de estandarte, todos solos gridando: "Batalla, batalla", y de tal son combatían la roca que a poca de hora la entraron por fuerça, destroçando y a todas partes firiendo hasta venir en alcance de la rica vandera imperial y prisión del alférez y de cinco cavalleros que tenía de guarda. En el cual instante yo, pavorosa, desadormecí por vía que más no me tomó el sueño; e desvelando mi pobre sentido, afligíame por venir en el cierto juizio de la tan miraglosa revelación; e según la interpretación que le dava, tristeza y alegría me acompañava. E con este solo cuidado engañava al tiempo, e aún me restava el día siguiente y la noche que en ál no pensava; y trabajado el espíritu me adormecía, e adormecida, segunda vez me veía en la roca, a las partes donde era en la alta cadira la muy esclarecida emperatriz, cubierta de un manto escuro, cubriente el estado doloroso de duelo, diziendo muy triste en guisa de planto: “¡La nuestra muy cara Ypodomía, amante, parte sana del nuestro grave dolor! No tardes lançar sobre ti las saldas armas de pacencia, e muestra tu firmeza contra las fuerças de la grand tristura que oy espera batallar contra tí. Desseas venir en conocimiento de los grandes secretos que traen celados los varios sueños: tal sabiduría es a tí ascondida e fuye de vós los mortales, la cual pues tanto procuras saber aunque sea en daño de tí, a nós plaze de te revelar. El emperador, señor de la roca, que viste en magnífico trono con las bolantes alas ardientes en flamas, es el alto Cupido, nuestro amado hijo del nuestro inflamado marido Vulcan, obedecido señor de la roca, que es la voluntat firme del leal amador. El cavallero esforçado que la conquistó es el tu desamante amado Troylos, por el cual sólo eres de nuestra valía, alcaide que solía ser de la nuestra roca. La antigua dueña que le dava la lança, es tu grande enemiga la olvidança. La que le dava el estandarte, es la deslealtat, que d'él no se parte. E el alférez mayor que levó él prisonero al su pavellón, es su falecido y desleal coraçón. Los otros presos cinco cavalleros son sus cinco sentidos, que solían guardar la nuestra roca de bien amar. La muy trabajada emperatriz que vees plañir y gritar de tal son, es la deesa mayor de las deesas que de Tetis Paris robó la mançana a Palas e Juno por la grand excelencia de su resplandor". E afinando en estas palabras, clarificada la tenebrosa cámara, en punto la deesa me desapareció.»

Esta larga omisión es exclusiva de $\mathbf{S a}$, ya que no es compartida por ninguno de los demás testimonios.

2) Además de esta omisión, en el aparato crítico se encontrarán otros muchos errores singulares de Sa frente al resto de los testimonios, que designamos con la abreviatura codd. (= MIFGBS). Estos errores de Sa provienen unos del manuscrito en que se basó nuestro autor, pero otros muchos se deben a error de lectura bien del propio Salazar o del copista de Mieres (errores del tipo: razon Sa: razones codd.; venga Sa: vengan codd.; Yncuba Sa: Ecuba codd.; tan Sa: tu codd.; tenia Sa: ternia codd.; Minis Sa: Minus codd.; del Fiolete Sa: del río Lete codd., etc.). 
3) Sa comparte con IFGBS una amplia omisión en la carta de Briseida a Troilo (Saquero-González Rolán, 2010, p.284): «¡Condenas a mí de la fe quebrantada por tí y porque me plogo de la guardar cuando la vi a tí quebrantar! Bien la quebrantaste cuando las selvas y los caminos eran allanados por los mis clamores por que no me consintiesses apartar de tí; e los oías y eras en el mi destierro», texto que sólo figura en $\mathbf{M}$.

4) En la epístola de Troilo a Briseida (Saquero-González Rolán 2010, p.273) figura la frase que transmite M: «toros de Mares que tenían los pies de azero, duendos y mansos», sin duda alguna expresión del original salido de las manos de Rodríguez del Padrón, puesto que el Bursario (segunda epístola) traduce el ovidiano aenipedes Martis boues (Her. VI, 32) como «los toros de Mares, que tenían los pies de azero». Pues bien, la referida frase de $\mathbf{M}$ ( toros...mansos) es omitida por IFGBS mientras que Sa sólo nos transmite una pequeña parte: «toros de Mares duendos.»

5) En esta epístola de Troilo a Briseida, a continuación de la frase anteriormente citada, aparece esta otra: «y adormecer al velante dragón», que nos la transmite M y también Sa, pero no IFGBS.

En la carta de Briseida a Troilo encontramos la secuencia «Batallan los sentidos, vencen las partes de mí. La vitoria es por el rudo cálamo», que se ha conservado en $\mathbf{M}$ y también en Sa, aunque éste omite la palabra 'rudo', pero es omitida por IFGBS. También omiten estos manuscritos la frase «desierta de aquesta manzanilla», que sí traen $\mathbf{M}$ y $\mathbf{S a}$.

Una última omisión común a IFGBS la encontramos al final de esta segunda carta cuando dice «en amor y membrança de mí, quebrantando la fe a los sueños, demuestra» que sí lo traen $\mathbf{M}$ y Sa.

6) Además de los ejemplos anteriormente señalados, son muchísimas las veces en que $\mathbf{M}$ y Sa coinciden en ofrecernos lecturas que contrastan con las que nos transmiten IFGBS. Ejemplos del tipo: noble M Sa: magnifico IFGBS; santas M Sa: sacras IFGBS; el hijo al padre M Sa: el fijo al padre e el padre al fijo IFGBS; dexadas M Sa: dexadas aparte IFGBS; la tal atrevençia e osadia M Sa: a tanta osadia IFGBS; y no estable M Sa: om. IFGBS; largo M Sa: luengo IFGBS; en tan grand fortuna M Sa: om. IFGBS; lesvias M (leydas Sa): om. IFGBS; conoçido M Sa: ofreçido IFGBS; grandes M Sa: om. IFGBS; valioso M Sa: valeroso IFGBS; reparte M Sa: repite IFGBS; en desfaçion M Sa: en despreçio IFGBS.

7) Con todo, el manuscrito que sirvió de base a las Bienandanzas presenta, frente a M, lecturas comunes con IFGBS, que sin duda remontan al original de Rodríguez del Padrón. Entre ellas podemos citar las siguientes.

(Carta de Troilo a Briseida) mano Sa IFGBS: om. M; hedificar los muros de la nuestra çibdad Sa IFGBS: hedificar la nuestra çibdat M; el divulgo 
de la tu fama Sa IGFBS: la tu fama M; la mengua Sa IFGBS: la enemiga M; $\tan$ ayna Sa IFGBS: $\tan \mathbf{M}$.

(Carta de Briseida a Troilo): puerto Sa IFGBS: parte M; relaçion Sa IFGBS: razon M; verdat Sa IFGBS: virtut M; respirando Sa IFGBS: respiando M; yedra Sa IFGBS: yerva $\mathbf{M}$, etc., etc.

8) Sa es el único que nos ha transmitido la lectura correcta del original: 'Pruto e Minus e Radamantes' frente a 'Pluton, Minus rradiantes' de M y 'Plato e Domus e Radiarco’ de IFGBS.

Si M se acercaba al original con la palabra 'yrza', Sa está mucho más cerca al ofrecernos 'ursa', frente a 'hygosa' ('higoza') de IFGBS.

9) Finalmente, Sa ofrece algunas lecciones comunes a IFGBS, introducidas por copistas catalanes al transcribir algún cancionero castellano. Así en la carta de Troilo a Briseida, frente a la lectura 'de tirar' de M, Sa nos da 'de toller', I 'atullir', FGB 'a tollar' y $\mathbf{S}$ 'a tollyr'; frente a la lección 'quemaste' de $\mathbf{M F}$, Sa nos ofrece 'brausaste', IS 'brusaste', GB 'abrusaste’.

Tras lo expuesto, pensamos que Sa, independientemente de los muchos errores que muestra, bien generados desde el origen o a través de las copias realizadas, procede de una familia a la que pertenecen también IFGBS, pero está mucho más cerca del original que todos ellos. Proponemos este stemma:

\section{EDICIÓN DEL TEXTO DE LAS DOS CARTAS COTEJADO CON EL RESTO DE LOS TESTIMONIOS MANUSCRITOS}

\section{TITULO $^{5}$ DE LA CARTA QUE TROYLOS ENBIO A BREÇEYDA SU ENAMORADA}

Breçeyda si mi esperança ${ }^{6}$ por mi se ordenó, e mi mano ${ }^{7}$ escrivió $^{8}$ a ti esta ${ }^{9}$ epís- $^{-}$ tola razón ${ }^{10}$ es que te non venga ${ }^{11}$ en plazer, piensa si de los tales oyr fueste ${ }^{12}$ mereçedora. E muchas vezes mi coraçón es puesto en trabajo, pensando quál fue la causa

\footnotetext{
${ }^{5}$ Título de la carta que Troylos enbio a Breçeyda su enamorada Sa: M (cf. Bursario, p. 270) letra de Troylo a breçayda I Epistola de Troyllo a briseyda F Epistola de Tryllo a breseyda $\mathbf{G}$ de Troylo a Breçayda S om. B.

${ }^{6}$ si mi esperança por mi se ordeno Sa: si mi corraçon penso y mi seso ordeno codd.

${ }^{7}$ mano Sa IFGBS: om. M.

${ }^{8}$ escriuio Sa IFGBS: escriue $M$.

9 esta: en esta IBSM om. FG.

10 razon Sa: razones codd.

11 venga Sa: vengan codd.

12 fueste Sa F: fuyste B fuste IS eres $\mathbf{M}$.
} 
o causas ${ }^{13}$ que tu coraçón mobieron dexar ${ }^{14}$ a Troylos ${ }^{15}$, aquel que te ${ }^{16}$ tanto amava, fijo del muy noble ${ }^{17}$ Príamo, Rey de Troya, e de la Reyna Yncuba ${ }^{18}$, hermano ${ }^{19}$ del buen $^{20}$ cavallero Hétor, en los quales tú ${ }^{21}$ sienpre falleçiste ${ }^{22}$, me han dicho ${ }^{23}$, nunca te faziendo ${ }^{24}$ ellos mençión del muy ynorme e orrible alebosía que tu padre Colcas se metió ${ }^{25}$ a fazer contra ellos, toda vondad ${ }^{26}$ e verguença e honor prosponiendo ${ }^{27}$, noteficando ella ${ }^{28}$ respuesta que los nuestros dioses $1 \mathrm{e}^{29}$ dieron a nuestros ${ }^{30}$ mortales $^{31}$ enemigos, lo qual ${ }^{32}$ dio grand esfuerço ${ }^{33}$ a ellos para non tardar su venida sobre la nuestra $^{34}$ çibdad de Troya. Ni fallo rasón ninguna por donde de ti olvidado sea, e no me debieras $^{35}$ trocar por Diomenis al qual yo soy çierto que amas, salvo que ${ }^{36}$ tus dulçes palabras, con afeçión de amor ${ }^{37}$ amostrabas, por donde me tenías tan costreñido e animado, heran ynfurtes ${ }^{38}$ e falsas, cabsa e malas e a donde son agora, Brasayda, las ynumerables promesas justas ${ }^{39}$ e sacramentos que $\tan ^{40}$ confeçión falsa e engañosa ${ }^{41}$ por el dios de Apolo, al qual ${ }^{42}$ nos llamamos Febo, otrosý por Noturno, ${ }^{43}$ dios de las aguas,

3 o causas Sa MIFGBM: om. $\mathbf{S}$.

14 dexar Sa IPGB: a dexar S de dexar $\mathbf{M}$.

15 Troylos Sa M: Troyllo FGB Troylo IS.

${ }^{16}$ te tanto Sa MBS: tanto te IFG.

17 noble Sa M: magnifico IFGB S.

18 Yncuba Sa: Ecuba codd.

${ }^{19}$ hermano Sa IF: y hermano $\mathbf{M}$ ermano $\mathbf{S}$ hermana $\mathbf{G}$ madre $\mathbf{F}$.

${ }^{20}$ buen Sa IFGBS: muy buen $\mathbf{M}$.

${ }^{21}$ tu Sa M: om. IFGBS.

22 falleçiste Sa: hallaste codd.

23 me han dicho Sa: mucho de algo codd.

24 faziendo (haziendo M) ellos Sa M: ellos faziendo FGBS ellos fizieron I.

${ }^{25}$ se metio Sa: se mostro M se mouio IFGBS.

${ }^{26}$ bondad Sa MI: verdat bondat FGBS.

27 prosponiendo Sa: posponiendo codd.

28 ella Sa IFGBS: la M.

29 le Sa M: om. IFGBS.

${ }^{30}$ nuestros Sa IFGBS: los nuestros $\mathbf{M}$

${ }^{31}$ mortales Sa: capitales codd.

32 lo qual Sa MB: la qual IS los quales FG.

33 dio grand esfuerço a ellos Sa IGBS: a ellos dio grande esfuerço $\mathbf{M}$ dieron grand esfuerço a ellos $\mathbf{F}$.

34 la nuestra Sa IFGBS: nuestra $\mathbf{M}$.

35 debieras Sa: devieses M devas IFGBS.

${ }^{36}$ salvo que Sa: salvo si codd.

${ }^{37}$ de amor Sa IFGBS: de amar M.

38 ynfurtes e falsas cabsa e malas Sa: infintosas y falsas captelosas y malas $\mathbf{M}$ infintosas cabtelosas falsas e malas I fintosas cautelosas falsas e males FG fintuosas cabtelosas e malas B enfyntosas cautelosas falsas e malas $\mathbf{S}$.

${ }^{39}$ ynumerables promesas justas Sa: innumerables promesas juras $\mathbf{M I}$ juramentos e innumerables promesas juros (juras BS) FGBS.

40 tan Sa: tu codd.

41 con afeçion falsa e engañosa por el dios Apolo Sa IFGBS: a mi me hazias por el dios Apolo M.

42 al qual Sa: al que $\mathbf{M}$ a quien IFGBS.

43 otrosy por Noturno dios de las aguas Sa: y otrosy por Neptuno dios de las aguas M otrosi por Neptuno a quien nos dezimos dios de las aguas FGB otrosy Netuno por quien nos llamamos dios de las aguas $\mathbf{S}$ otrosi por quien nos llamamos dios de las aguas I. 
las quales fueron edeficar los muros ${ }^{44}$ de la nuestra çibdad, por las santas ${ }^{45}$ reliquias troyanas, e por nuestro ${ }^{46}$ Paladión $^{47}$ el qual es fecho a la ymajen de Júpiter ynfinitas vezes tomados dioses non çesantes ${ }^{48}$ me feziste e prometiste junta fee ${ }^{49}$. E mas ¿qué te puedo dezir Breçayda?, pues veo cosa $\operatorname{ser}^{50}$ natural pareçer el fijo ${ }^{51}$ al padre. E e así non he ${ }^{52}$ yo a maravilla ser engañado ${ }^{53}$ segund $^{54} \mathrm{mi}$ padre a tu engañadora segund el tuyo. E ya anda el diburgo ${ }^{55}$ de la tu fama por el ayuntamiento de los caballeros ${ }^{56}$, e dueñas de Troya te han diburgado $\operatorname{commo}^{57}$ es ya tu fecho ${ }^{58}$ entre ellos ${ }^{59}$ que todas las otras cosas dexadas ${ }^{60}$, non departen ni fablan de $\mathrm{al}^{61}$ en los sus solazes e burlan ${ }^{62}$ e retraen ${ }^{63} \mathrm{de}<\mathrm{n}>$ tro y los por que te tanto amaba. E miémbrome ${ }^{64}$ agora de aquella ${ }^{65}$ postrimera noche que por ti manimos ${ }^{66}$ en uno, $\mathrm{e}^{67}$ entraban los rayos de la luna ${ }^{68}$ por las finiestras ${ }^{69}$ de la nuestra cámara, e quexabas te tu pensando que era la mañana, e dezías con falsa ${ }^{70}$ lengua commo en manera de querella: «iO Febus ${ }^{71}$ de la claridad del erradiante ${ }^{72}$ divino $^{73}$, los quales, faziendo vuestro curso ${ }^{74}$, vos mostrades e venides en pos de las tiniebras ${ }^{75}$ ! De la natural ora mueban vos a piedad ${ }^{76}$ los grandes ge-

\footnotetext{
44 edeficar los muros de la nuestra cibdad Sa IFGBS: hedificar la nuestra çibdat $\mathbf{M}$.

${ }^{45}$ santas Sa M: sacras IFGBS.

46 nuestro: $\mathrm{om}$. $\mathbf{S}$.

47 Paladion: Palidion I.

48 çesantes Sa M: çesante IFGB çesando $\mathbf{S}$.

49 junta fe Sa: y juraste codd.

50 cosa ser Sa IBS: cosa esser FG ser cosa M.

${ }^{51}$ el fijo al padre Sa M: el fijo al padre e el padre al fijo IFGBS.

52 non he yo a maravilla ser $\mathbf{S a}$ : non he a maravilla ser $\mathbf{M}$ non es maravilla yo ser $\mathbf{I}$ assi non es maravilla yo ser FGBS.

53 engañado: engañada $\mathbf{G}$.

${ }^{54}$ segund el tuyo e ya anda Sa: segun el tuyo ya anda IFGBS segund que el tuyo ya anda $\mathbf{M}$.

55 el diburgo de la tu fama Sa: el divulgo de la tu (tuya FG su B) fama IFGBS.

56 de los caballeros e dueñas de Troya te an diburgado Sa: de los caballeros e dueñas de Troya e te han (e tan IBS) divulgado IFGBS de los cavalleros de Troya y a las dueñas y donzellas tan divulgado M.

${ }^{57}$ commo Sa MIF: e comun GBS.

58 tu fecho Sa: el tu fecho IFGBS el clamor de la tu fama y fecho M.

${ }^{59}$ entre ellos Sa IFGBS: entre ellos y ellas $\mathbf{M}$.

${ }^{60}$ dexadas Sa M: dexadas aparte IFGBS.

${ }^{61}$ de al Sa IFGBS: en al M.

62 burlan Sa IFGB: burlas $\mathbf{S}$ burla $\mathbf{M}$.

${ }^{63}$ retraen Sa MI: trahen burla $\mathbf{F}$ retraen de Troylo BS trahen de Troylo beffa $\mathbf{G}$.

${ }^{64}$ mienbrome agora Sa M miembrome yo agora GBS miembro yo me yo agora $\mathbf{F}$ mienbrome yo I.

${ }^{65}$ de aquella Sa IFGBS: de la $\mathbf{M}$.

${ }^{66}$ manimos en uno Sa M: en uno manimos (magnimos IFG) IFGBS.

67 e Sa M: om. IFGBS.

${ }^{68}$ de la luna Sa IFGBS: de la claridat de la luna $\mathbf{M}$.

${ }^{69}$ por las finiestras Sa IFGBS: por la finiestra M.

70 con falsa lengua Sa: lengua codd.

${ }^{71}$ o Febus Sa: o fuegos codd.

72 erradiante Sa: radiante (radiant I) codd.

${ }^{73}$ divino Sa MIS: diurno FGB.

${ }^{74}$ vuestro curso $\mathbf{S a}$ : vuestro ordenado curso M vuestro curso ordenado IFGBS.

75 de las tiniebras de la natural ora Sa IFGBS: de la conturbal hora de las tiniebras $\mathbf{M}$.

${ }^{76}$ a piedad Sa: agora a piedat MFGB agora piedat IS.
} 
midos e dolores ${ }^{77}$ e sospiros de la mezquina Breseyda, e çesad tan ayna de mostrar ${ }^{78}$ la vuestra fuerça ${ }^{79}$ del dicho grand poder! dando lugar a Breçayda que repose algund tanto con Troylos ${ }^{80}$, su leal amigo!». E dezías ${ }^{81}$ tú, Breçayda: «¡Quándo ${ }^{82}$ me tenía ${ }^{83}$ por bien aventurada si yo ${ }^{84}$ agora sopiese la arte ${ }^{85}$ mágica, que es la alta çiençia de los mágicos, por lo qual ${ }^{86}$ han pode de fazer tornar ${ }^{87}$ del día noche e de la noche día por sus sabias palabras e maravillosos sacrifiçios! ¿E qué non sé ${ }^{88}$ yo agora tan poderosa de fazer aquesto ${ }^{89}$ e costreñirte apremiar los vigorosos rayos ${ }^{90}$ del día, commo fizo ${ }^{91} \mathrm{Jú}^{-}$ piter creçer la noche en que Hércoles naçió, segund cuenta Daymira en su epístola ${ }^{92}$, e commo fizo Medea con sus encantamentos venir los muy bravos toros ${ }^{93}$ de Mares, duendos al yugo de mançebo griego, e adormeçer ${ }^{94}$ al velante dragón? E por qué no es agora ${ }^{95}$ así a mí posible de toller ${ }^{96}$ la fuerça al día? ${ }^{97}$. E yo, movido a piedad por las quexas que tú mostrabas, levante me e salí de la cámara, e vi que hera la ora de la media noche, quando el mayor sueño tenía amansadas todas las criaturas; e vi el ayre acallentado $^{98}$, e ruçiadas las fojas de los árboles de la guerta del Ylilión ${ }^{99}$ alcáçar del rey, mi padre, e aquedadas ${ }^{100}$ que non se mobían, de guisa cosa alguna e non obraban ${ }^{101}$ de su vertud. E e torné ${ }^{102}$ yo a ti e díxete: «Breçayda, non te quexes, que ${ }^{103}$

77 dolores e sospiros Sa: dolorosos sospiros codd.

78 de mostrar Sa MB: mostrar IFGS.

${ }^{79}$ la vuestra fuerça del dicho grand poder Sa: la fuerça del vuestro grand poder codd.

${ }^{80}$ Troylos Sa M: Troylo (Troyllo FB) IFGBS.

${ }^{81}$ e dezias Sa MFGB: dezias IS.

${ }^{82}$ quando Sa: quanto I o quanto MFGBS.

83 tenia Sa: ternia codd.

${ }^{84}$ yo agora Sa IFGBS: agora yo $\mathbf{M}$.

85 la arte Sa M: el arte IFGBS.

${ }^{86}$ por lo qual Sa: por la qual codd.

87 fazer tornar del dia noche e de la noche dia $\mathbf{S a}$ : de tornar el dia noche e la noche dia IFGB de tornar la noche dia e el dia noche $\mathbf{S}$ de hazer del dia noche y de la noche dia $\mathbf{M}$.

88 e que non se yo agora Sa: e que non soy agora I e porque no soy agora $\mathbf{S}$ e porque non soy FGB e porque no so yo agora $\mathbf{M}$.

${ }^{89}$ fazer aquesto e costreñir Sa IFGB: fazer e costreñir $\mathbf{S}$ fazer costreñir $\mathbf{M}$.

90 rayos del dia Sa: rayos de la claridat del dia codd.

91 commo fizo Jupiter creçer la noche Sa FGB: commo fizo Jupiter çesar la noche IS como hizo Jupiter que hizo creçer la noche $\mathbf{M}$.

92 epistola Sa IFGBS: letra M

93 toros de Mares duendos Sa: toros de Mares IFGBS toros de Mares que tenian los pies de azero, duendos e mansos $\mathbf{M}$.

94 e adormeçer al velante dragon Sa M: om. IFGBS.

95 agora asi Sa: agora IFGBS om. M.

${ }^{96}$ de toller Sa: a toller FGB a tollyr $\mathbf{S}$ atullir I de tirar $\mathbf{M}$.

${ }^{97}$ al dia Sa M: del dia IFGBS.

98 acallentado Sa B: acalentado IFGS acallantado M.

99 del Ylilion alcaçar del rey mi padre Sa: del Ylion alcaçar (alcassar G) del rey mi padre FGB del Ylyon alcaçar (alcaçer I) de mi padre IS del alcaçar del rey, mi padre, llamado Ylion M.

100 aquedadas Sa: aquedados FGS quedados IB quedas $\mathbf{M}$.

101 obravan Sa MS: obrava IFGB.

102 torne yo a ti Sa: torne a ty $\mathbf{M}$ torneme a ti IFGBS.

103 que Sa MS: ca IFGB. 
non es el día commo tú piensa.» E fueste tú muy alegre con las nuebas que te aduxe $\mathrm{e}^{104}$. E aún me mienbra ${ }^{105}$ las palabras que me dexiste, corriéndote las lágrimas por las tus maxillas ${ }^{106}$ al tienpo de la tu partida de la nuestra çibdad dixaendo ${ }^{107} ¡$ Oy ynfante ${ }^{108}$, e allá me maravillo ${ }^{109}$ yo mucho por grand fecho ${ }^{110}$ la mengua ${ }^{111}$ que tú ${ }^{112}$ feziste contra $^{113}$ la Bedigual ${ }^{114}$ tu padre el rey Miso ${ }^{115}$ de Alcameña, cruelmente lo descabeçando ${ }^{116}$ por aver el amor del rey Minis ${ }^{117}$ de Creta, si lo tú tanto amabas como yo amo a Troylos ${ }^{118}$. Nin tengo por maravillosa fazaña de te dar el ama, la tal atrebençia ${ }^{119} \mathrm{e}$ osadía, ca juro yo por los nuestros ${ }^{120}$ dioses Venus e Cupido, que son poderosos de amor, que por escusar yo la tal ${ }^{121}$ partida no me dudaría ${ }^{122}$ el coraçón de fazer semejant o mayor mengua, e pues yo pienso ${ }^{123}$ agora, Braçayda, que tú as vevido de mi aquella $^{124}$ agua del Filote ${ }^{125}$ que corre e pasa por las tenebrosas honduras de los ynfiernos; lo qual dizen los nuestros autores en sus fazañas que fazen ${ }^{126}$, aquellos ${ }^{127}$ que dél beven, olvidar e foyr de la memoria todas las cosas pasadas, por que tan ayna ${ }^{128}$ ovieses olvidado todas las juras ${ }^{129}$ e promesas que me feçiste a mi que tanto ${ }^{130}$ amado. Alexoses ${ }^{131}$ de aquí, e non es cosa traediza ${ }^{132}$, e mas ni fizo ${ }^{133}$ aquí meneste el agua

\footnotetext{
104 te aduxe Sa IFGB: te truxe $\mathbf{S}$ te yo dixe $\mathbf{M}$.

105 me mienbra las palabras Sa: me miembra mas las palabras $\mathbf{M}$ me miembro de las palabras $\mathbf{S}$ miembrome de las palabras IFGB.

106 por las tus maxillas Sa IFGBS: por las tu falssas maxillas M.

107 çibdad dixaendo oy Sa: çibdat deziendo: o IFGBS çibdat troyana: o M.

108 ynfante Sa: infanteçilla IFGBS infançilla $\mathbf{M}$.

109 e alla maravillo yo mucho por gran Sa no me maravillo yo nin he por grand codd.

110 fecho Sa IFGBS: fazaña M.

111 la mengua Sa IFGBS: la enemiga $\mathbf{M}$.

112 tu Sa M: om. IFGBS.

113 contra $\mathbf{S a}$ : en cortar IFGBS en tomar $\mathbf{M}$.

114 la Bedigual Sa: la vedija (vedria G) codd.

115 tu padre el rey Miso de Alcameña Sa: a tu padre el rey Niso de almenia (almeria FG) IFGBS al rey Visota, padre de Alcatuena M.

116 cruelmente lo descabeçando Sa IFGB: cruelmente lo descabeçaste $\mathbf{S}$ porque cruelmente fue descabeçado $\mathbf{M}$.

117 Minis Sa: Minus codd.

118 a Troylos Sa: a Troylo (Tryllo FG) IFGBS Troylos M.

119 la tal atrebençia e osadia Sa M: tanta (a tanta I) osadia IFGBS.

120 nuestros Sa M: om. IFGBS.

121 la tal Sa IFGBS: tal M.

122 no me dudaria el coraçon de fazer semejant o mayor mengua Sa: a mi coraçon no dubdaria hazer semejante y aun mayor enemiga $\mathbf{M}$ no me dudaria elcoraçon fazerlo semejante IFGBS.

123 yo pienso agora $\mathbf{S a}$ : agora piense $\mathbf{M}$ agora te digo IFGBS.

124 aquella Sa M: om. IFGBS.

125 Filote Sa: del rio Lete codd.

126 fazen Sa IS: haze M faze FGB.

127 aquellos que del Sa IFGBS: los que del M.

128 tan ayna Sa IFGBS: $\tan \mathbf{M}$.

129 todas las juras e promesas Sa: todas las juras promesas sacramentos IFGBS todas las cosas y juras y promesas y sagramentos $\mathbf{M}$.

130 tanto amado Sa: tanto te (te tanto MS) amava codd

131 alexos (alenxos M) Sa M: lexos IFB lenxos $\mathbf{S}$ lexes $\mathbf{G}$.

132 cosa traediza Sa: cosa creedera IFGBS cosa posible ni creedera $\mathbf{M}$.

133 ni fizo Sa IFGBS: no hizo M.
} 
del dicho Fiolete ${ }^{134}$, ni alguna otra cosa de aquellas que prueba ${ }^{135}$ su poderío de aque$11 a^{136}$ çédula a quien es recomendada la remisçençia de la capaçidad, salvo la movible e non estable voluntad, e la poca firmeza del tu falso coraçón. E ama agora Diomides a ti, Bresayda ${ }^{137}$, e loe la falsa ${ }^{138}$ presençia. Que non pasarán ${ }^{139}$ los tienpos muchos que por él non sean aprobados los dichos en la mi epístola contenidos, e aquellos ${ }^{140}$ que yo fallesco de mostrar de la tu poca gostançia e mobible voluntad, brebemente lo él soplirá $^{141}$ e acreçentará, ca el verdadero fiel amor largo ${ }^{142}$ tienpo lo mostrara ${ }^{143}$. E non dilato ni fago más larga razón en esta materia deslealtad, la qual todos mis sentidos turban $^{144}$ e ocupan ${ }^{145}$, e más omillmente soplico e ynploro a los nuestros dioses, que por sus santas admiraciones ${ }^{146}$ e obras dignas de perpetual memoria fueron e son ya mortales $^{147}$, que tu ynorme ${ }^{148}$ deslealtad desaborrescan e te fagan prinçipal ${ }^{149}$ conpañera de aquella que las ynfernales rabias ${ }^{150}$ padeçen por semejantes malefiçios crímines. $\mathrm{Ca}$ non heres ${ }^{151}$ tú dina ${ }^{152}$ de pena de las fijas del rey Dánao, de Argos, las quales cruelmente mataron sus maridos, ni que otras muchas que padeçen ${ }^{153}$ por semejantes.

\section{TITULO $^{154}$ DE LA RESPUESTA QUE BREÇEYDA ENBIO A TROYLOS SU ENAMORADO EN RESPUESTA DE LA CARTA QUE LE EL YNBIO CON SUS SALVAS}

A tí, segundo Étor, conquistador ${ }^{155}$ de la fama, caudillo de los troyanos, esparzidor de la sangre griega, la ofendida ${ }^{156}$ de ti Breseyda que por tu epístola non saludas-

\footnotetext{
134 Fiolete Sa: rio (rey I) Lete codd.

135 prueba Sa M: pruevan IFGBS.

136 de aquella Sa: aquella M e aquella IFGBS.

137 Bresayda Sa: Breçayda MIS Briseyda F Brizeyda G Breseyda B.

138 falsa presençia Sa IFGBS: presençia falssa M.

139 que non pasaran Sa FGBS: que non pasara I ca soy çierto que non pasaran $\mathbf{M}$.

140 aquellos Sa: aquello codd.

141 soplira Sa MI: suplicara FGBS.

142 largo Sa M: luengo IFGBS.

143 mostrara Sa: muestra codd.

144 turban Sa: turba MFGB travan $\mathbf{S}$ trava $\mathbf{I}$.

145 ocupan Sa S: ocupa MIFGB.

146 admiraciones Sa M: administraçiones IFGBS.

147 ya mortales Sa: inmortales codd.

148 ynorme Sa I: innorme M enorme FGBS.

149 prinçipal compañera de aquella Sa: prinçipal en conpañia de (a BS e G) aquellos IFGBS parçial de aquellas $\mathbf{M}$.

${ }^{150}$ rabias Sa IFGBS: furias y ravias $\mathbf{M}$.

151 heres (eres M) Sa M: eras IFGBS.

152 dina Sa: menos digna codd.

153 que padeçen por semejantes (lo semejante M) SM: que las semejantes ravias padeçen IFGBS.

154 Titulo de respuesta que Breçeyda enbio a Troylos su enamorado en respuesta de la carta que le el ynbio con sus salvas Sa: Braçayda a Troylo I Letra de Briseyda a Troyllo FG om. BS La carta....M (cf. Bursario, p. 277).

155 conquistador Sa M: aquistador IFGBS.

156 la ofendida de ti Sa IFGBS: de ty offendida $\mathbf{M}$.
} 
te $\mathrm{e}^{157}$, con la presente enbío saludes. Vibien ${ }^{158}$ los pasados por gloriosa fama; e mueren los vinientes ${ }^{159}$ por trabaxosa vida. Aquí presente ${ }^{160}$ bolvieron mi pensamiento, la voluntad me requiere ante de la escriptura darle estrenimiento e mano ${ }^{161}$ a la ayuda ${ }^{162}$ experpada; la razón lo desbía diziendo primeramente deve ${ }^{163}$ salvarle la fama en tan grand fortuna ${ }^{164}$. ¿ Aquel a quál puerto ${ }^{165}$ lançaré mis anclas? ¿e daré fin a la penosa vida o salvación a la de mi grand ${ }^{166}$ fama? Vevir es morir, a finar ${ }^{167}$ la vida es sepoltura la fama. E ninguna vía es a mi segura. ¿Quál seguiré? ¿e usaré del cochillo o del rudo tálamo? E vatallan ${ }^{168}$ los sentidos, e vençen de mí. Las partes de mi la vitoria es por el tálamo; pues ¿qué tanto escrevir? ¿qué escreviré? Mezquina, ${ }^{169}$ o qué diré, no lo sé. Abunda ${ }^{170}$ la justiçia para me poder salvar, e falleçe $\mathrm{e}^{171}$ la sabiduría para lo saber ${ }^{172}$ mostrar. ¡Ay ${ }^{173}$, que las leydas ${ }^{174}$ musas me negaron su fabor e las aguas ${ }^{175}$ del Encadia ${ }^{176}$ que fizieron prudente a Salamón ${ }^{177}$ non justo Breçayda!. ¿ Qué pensaré que la sentible ${ }^{178}$ pasión me robó ${ }^{179}$ la discreçión? ¿Qué fablaré, que non oso contrastar a quien me solía mandar? ¡O afurtunada ${ }^{180}$ !, ¿qué faré o a quién reclamaré? ¡O menbrança sola de mi deseado Troylos ${ }^{181}$, autor ${ }^{182}$ de la estudia letra robadora ${ }^{183}$ ! De mi lealtad e dalogar a la por tí condenada Breçayda que fable e escriva ${ }^{184}$ de sí ${ }^{185}$, e se demuestre ${ }^{186}$ ser yno-

\footnotetext{
157 saludaste Sa MFGB: salvaste IS.

158 vibien Sa: biven codd.

159 vinientes Sa: bivientes codd.

160 aqui presente bolvieron mi pensamiento Sa: a que parte.....pensamiento $\operatorname{codd}$.

161 darle estrenimiento e mano Sa: darle la escriviente mano codd.

162 a la ayuda esperpada Sa: a la ayuda espada codd.

163 deve Sa I: se deve FGBS deva M.

164 en tan grand fortuna Sa M: om. IFGBS.

165 puerto Sa IFGBS: parte M.

166 grand Sa: divulgada IS ingrata FG denegrida MB.

167 a finar Sa IB: e finar MFGS.

168 vatallan los sentidos e vençen de mi las partes de mi la vitoria es por el tálamo (rudo calamo M) Sa M: om. IFGBS.

169 mezquina o que dire no lo se Sa IFGBS: mesquina no lo se $\mathbf{M}$.

170 abunda la justiçia Sa IS: basta la justiçia FGB bastame asaz la justiçia $\mathbf{M}$.

171 falleçe Sa IFGBS: falleçeme M.

172 lo saber Sa M: lo poder IFGBS.

173 ay Sa MFGB: ay ay IS.

174 leydas Sa: lesvias M om. IFGBS.

175 e las aguas Sa IFGBS: ay que las aguas M.

176 Encadia Sa: Leocadia (Lecadia I) codd.

177 Salamon Sa: Serpio M Sapo IS Saeno F Saono G Saonogusto B.

178 sentible Sa MFGB: senblante IS.

179 robo Sa M: roba IFGBS.

180 afortunada que fare Sa M: afortunada e que dire o que fare IS o fortunada que fare o que dire FG o fortuna que dire o que fare $\mathbf{B}$.

181 Troylos Sa M: Troylo IBS Troyllo FG.

182 autor (actor $\mathbf{M}$ ) Sa M: resçebidor I rezebidor $\mathbf{S}$ escrividor $\mathbf{F G}$ escrevidor $\mathbf{B}$.

183 robadora Sa MFGB: robador IS.

184 escriva Sa IFBS: scrive $\mathbf{G}$ responda $\mathbf{M}$.

185 de si Sa: en defensa de si codd.

186 demuestre Sa M: muestre IFGBS.
} 
çente por aquel rudo estilo que las sinples mugeres con poco saber traer solemos en nuestra escritura. Oyas ${ }^{187}$ primeramente la que sin ser oyda condenas, e non des tan en punto creençia a la finiestra de mi relaçión ${ }^{188}$. ¡O tú, cavallero constante, vençedor de las fuertes vatallas, que las fuerças de Archiles non temes, ni los sotiles engaños de Ulixes. Non te consientes vençer de leves e engañosas palabras que siguen en pos de los vientos e careçen de toda verdad ${ }^{189}$. E considera bien el fin de aquellas ${ }^{190}$ dónde ovieron su naçimiento. E sy de los cavalleros e dueñas de Troya, non les deves dar fe, que son enemigos de mi padre Colcas, e non es buen testigo en contra ${ }^{191}$ del fijo el capital ${ }^{192}$ enemigo del padre. E sy de la hueste a ti adv $<$ e $>$ rsaria, ¿qué te muebe a la creençia? Commo el sabio ${ }^{193}$ enemigo sienpre estudia e piensa cómmo pueda enojar a su enemigo del fiel amigo lo fazer contrario, e non te mueba ${ }^{194}$ ayrar contra mí la nueba requesta que Diomedes me fizo de amores. Al qual çiertamente te dizes que amo, que fuyr la deslealtad que me condenas e non venir en despreçio de un senblante rey, non sin grand misterio aunque ynprobiso, yo le di a tan savia respuesta que toda persona ${ }^{195}$ entienda juzgar ygual de si leçion ${ }^{196}$ deziendo: «E e muy poderoso rey, las profeçías ${ }^{197}$ de vuestros amores al presente yo ${ }^{198}$ non menospreçio, ni me plaze de las reçebir, que ${ }^{199}$ yo dispuesto en tal guisa de mi coraçón que non me conbiene responder otra mente ${ }^{200}$ abrán exçelençia ${ }^{201}$.» E lo qual si error ${ }^{202}$ o maldad cometí, quiero que tú solo juez seas de mi. E quando por tu discreta memoria deliberadamente lo quesieres tratar, fallarás que husar de çilençio yo non podría con un tan magnífico rey sin tocar en grand desmesura, pues que yo debiese menospreçiar sus palabras e venir en muy esquiba ${ }^{203}$ e agra respuesta. ¿Qué restava ${ }^{204}$ a las dueñas silvestres ${ }^{205}$ que punto no saben de gentileza, en senblantes requestas suelen ofender a los gentiles omnes, sy después dellos ${ }^{206}$ muy ofen-

\footnotetext{
187 oyas Sa FGBS: oygas I oye M.

188 relaçion Sa IFGBS: razon $\mathbf{M}$.

189 verdad Sa IFGBS: virtut $\mathbf{M}$.

190 de aquellas Sa IFGBS: de aquellos que la tal relaçion te hizieron $\mathbf{M}$.

191 en contra del fijo Sa: contra el fijo IFGBS en contrario del hijo M.

192 el capital enemigo Sa MFGB: el enemigo capital IS.

193 el sabio enemigo sienpre estudia y piensa commo pueda (puede) M enojar a su enemigo del (y del M) fiel amigo lo fazer contrario Sa M: el sabio enemigo sienpre se trabaja de fazer lo contrario e del fiel amigo tractar lo avieso (hoviesse FG adverso S) IFGBS.

194 non te mueba ayrar Sa IFGBS: no te muevas ayrado M.

195 persona entienda juzgar Sa: persona entendida juzgara codd.

196 de si leçion Sa: de silençio codd.

${ }^{197}$ profeçias Sa: profiertas M ofertas IFBS offiertas F.

198 yo Sa M: om. IFGBS.

199 que Sa IFGBS: ca M.

200 otra mente Sa M: de otra guisa IFGBS.

201 abran exçelencia Sa: a vuestra excelençia codd.

202 error Sa IFGBS: yerro M.

203 esquiva e agra Sa: agra y esquiva $\mathbf{M}$ esquiva e muy agra $\mathbf{S}$ agra IFGBS.

${ }^{204}$ restava Sa M: resta $\mathbf{S}$ restaria IFGB.

205 silvestres Sa M: silvestras IFGBS.

206 e sy despues dellos muy ofendidos Sa: e despues ser dellos muy offendidas IFGBS y ser despues dellas muy offendidos $\mathbf{M}$.
} 
didos? Esto non conbenía a dama ${ }^{207}$ de onor, e menos a la noble ${ }^{208}$ en linaje que poder $^{209}$ naçida e criada en tanta destreza. Conoçido yerro en que me veo caer por solo venir en loores de mí, mas non en ofensa alguna de ti. Nin te vença la yra por que al dar a ti de la salva yo aya perdido el guante de mi mano diestra, e después sea visto $^{210}$ en poder de aquel. El qual fue perdido, mas non ofreçido; fallado, mas non otorgado; e non syn gran verguença e yo podiera ${ }^{211}$ venir en busca o demanda de un pobre guante en presençia ${ }^{212}$ de tantos señores. Por ventura ${ }^{213}$ te fue en grandeza alabança ${ }^{214}$ proferta $^{215}$ que me fizo de tu aquistado ${ }^{216}$, e respuesta que al mesmo dimenador ${ }^{217}$ que fue de aquel suplicante en voz del señor a mi ${ }^{218}$, que oviese menbrança de quien lo oviera e avía de mi, ofreçiéndome el preso $^{219} \operatorname{coser~de~Troylos~}^{220}$, aquel que a mi e yo tanto amaba; al qual sin error ${ }^{221}$ te fazer, estudiosamente yo $^{222}$ respondí, referiendo a ti, non a él, mis palabras ${ }^{223}$ que desamar e olvidar non podía un tan verdadero de mi amador. Lo qual, si bien quisieres pensar aver debrías ${ }^{224}$, en grado e considerando quien conocido ${ }^{225}$ cavallo ha non es $^{226}$ en poder de tu enemigo que pueda ${ }^{227}$ en él batallar contra ti; segúnd la grand bondad de aquel non dudo ${ }^{228}$ fiziera, e non dubdes tú si tan en punto ${ }^{229}$ él no se comedia a melo enbiar, por esta sola causa ${ }^{230}$ que yo non tardara de lo demandar. Si oviste en agravio $^{231}$ por lo yr vesitar el día de la déçima ${ }^{232}$ quarta vatalla, quando a él e al rey Amenalao ${ }^{233}$ e al enperador de la hueste, Agame-

\footnotetext{
207 dama Sa M: dueña (duenya FS) IFGBS.

208 noble Sa M: muy noble IFGBS.

${ }^{209}$ que poder Sa: Ypodamia MS Ypodemia IFGB.

210 visto Sa FGBS: venido MI.

211 podiera Sa MS: podia IFGB.

212 en presençia de tantos señores Sa: ante tantos señores $\mathbf{M}$ en presençia de tantos señores yo lo (si la FG sy lo B) fiziera IFGBS.

213 por ventura Sa M: si por ventura IFGBS.

214 alabança Sa: la vana codd.

215 proferta (profierta M) Sa M: oferta (offerta G ofierta F) IFGBS.

216 aquistado Sa: aquistado coser (cosser $\mathbf{F}$ cocosser G) FGB requestada cosel IS conquistado coser $\mathbf{M}$.

${ }^{217}$ que al mesmo dimenador que fue de aquel suplicante Sa: que di al mesmo traedor de aquel suplicante

M que al moço di movido que fue de aquel suplicante IFGBS.

218 a mi Sa M: om. IFGBS.

219 preso coser (cosel IS) Sa IFGBS: presto coser M.

220 de Troylos Sa M: om. IFGBS.

${ }^{221} \sin$ error te fazer Sa: $\sin$ tanto error te fazer IFGBS syn error terreçer $\mathbf{M}$.

222 yo Sa M: om. IFGBS.

223 palabras que Sa M: palabras diziendo que (que om. B) IFGBS.

224 debrias Sa M: devieras IFGBS.

225 conoçido Sa M: ofreçido IFGBS.

${ }^{226}$ non es en poder Sa: ya no es en poder $\mathbf{M}$ non era en poder IFGBS.

${ }^{227}$ que pueda en el batallar Sa: para que en el pueda batallar $\mathbf{M}$ a que (quien $\mathbf{F}$ qui $\mathbf{G}$ ) pudiese (podiesse

FGB) batallar IFGBS.

${ }^{228}$ non dudo fiziera Sa FGB: non dubdo que te fiziera IS no dever fiziera $\mathbf{M}$.

229 en punto Sa IFGBS: ayna $\mathbf{M}$.

${ }^{230}$ por esta sola causa Sa M: por solo çessar (çesar B) esta causa IFGBS.

231 en ( por $\mathbf{M}$ ) agravio $\mathbf{S a} \mathbf{M}$ : en desgrado $\mathbf{S}$ en grado IFGB.

232 deçima quarta Sa M: quarta deçima (XIIII ${ }^{\mathrm{a}}$ F) IFGBS.

233 Amenalao Sa: Menalao codd.
} 
nón, feziste en tierra ${ }^{234}$ venir con la punta ${ }^{235}$ de tu pavorosa lança, mortalmente feridos, non lo devedes aber que ${ }^{236}$, segúnd creo sabes ${ }^{237}$, de parada ${ }^{238}$ la cruel vatalla por retraer de Apolo a la casa o çibdad ${ }^{239}$; los príncipes dantos ${ }^{240}$ entraron luego en consejo secreto en la çercana ${ }^{241}$ tienda $^{242}$, por ser de los reyes el más mal ferido, e con gran sentimiento tratando vengança. E yo, resperando ${ }^{243}$ en mucha alegría por conoçer que tú solo heres el pavor ${ }^{244}$ e la nueba del canpo, vino a mi el barrunto del contra ti mobido trabtado $^{245}$, que del todo me entresteçió; el qual por saber e a tí rebelar, fengí yr en vista del tu conquista, do por sola venida de mi todos fueron e en continuo siliençio; del qual sy sabidor heres, non te deves asegurar, e sey ${ }^{246}$ leal amador ${ }^{247}$, ni presto a mi condenar. Escrives ${ }^{248}$ non aver agran maravilla ser engañado segund fue ${ }^{249}$ tu padre, e yo engañadora segúnd ${ }^{250}$ el mío. Non debrías ${ }^{251}$ por el yerro ${ }^{252}$ dubdoso del padre condenar la çierta ${ }^{253}$ ynoçençia del fijo, commo a las debegadas ${ }^{254}$ el viçioso padre engendra virtuoso fijo, encontrariamente ${ }^{255}$. Si bien entendiste la antigua ystoria del muy viçioso rey Danaodargos, que en fin de tu letra escreviste, fallarás que en los viçios su fija respuesta ${ }^{256}$ virtuosamente le desapareçió ${ }^{257}$. E así que non es perpetua ${ }^{258}$ razón pareçerse el fijo al padre e ya sea naturalmente pareçer le debiese ${ }^{259}$ non es contra naturaleza quel hermano menor debiese pareçer al mayor. E si Paris, tu hermano mayor, quebrantó la fee a la ninfa Enone en la $\operatorname{mar}^{260}$ a Elena, bien se sigue ${ }^{261}$ tú, ser

\footnotetext{
234 en tierra venir Sa M: venir en tierra IFGBS.

235 con la punta de tu pavorosa lança (espada FG) mortalmente feridos Sa IFGBS: mortalmente feridos con la punta de tu pavorosa lança $\mathbf{M}$.

${ }^{236}$ que Sa: ca IFGBS om. M.

${ }^{237}$ sabes Sa M: sabras IFGBS.

238 deparada Sa: despartida $\mathbf{M}$ retrayda IFGBS.

239 casa o çibdad Sa: casa ocçidia codd.

240 dantos Sa: danos MG daçios IFGBS.

241 çercana Sa M: mas çercana IFGBS.

242 tienda Sa: tienda de aquel codd.

243 resperando Sa: respirando IFGBS respiando $\mathbf{M}$.

244 el pavor e la nueba Sa I: el pavor e nueva (e $\mathrm{om}$. F) FGBS la nueva y el pavor M.

245 trabtado Sa: tractado IFGBS trato M.

246 sey Sa: si codd.

${ }^{247}$ leal amador ni presto a mi condenar Sa: leal amador ni por esto a mi condenar $\mathbf{M}$ leal a mi amador non condenar IF leal amador non condenar GBS.

248 escrives non aver a gran maravilla ser (ser om. B) Sa IFGBS: no esquives no aver a maravilla ser M.

249 fue Sa M: om. IFGBS.

250 segund Sa IFGBS: segund que $\mathbf{M}$.

251 debrias Sa M: devieras IFGBS.

252 yerro Sa M: error IBS amor FG.

253 çierta Sa MFGB: om. IS.

254 a las debegadas Sa: a las devegadas IS a las vegadas MFGB.

255 encontrariamente Sa: e contrariamente $\mathbf{M}$ e por el contrario IFGB por el contrario $\mathbf{S}$.

256 Respuesta Sa: Ypermesta codd.

257 desapareçio Sa: despareçio codd.

258 perpetua Sa IFGBS: propria $\mathbf{M}$.

259 debiese Sa M: deva IFGBS.

260 en la mar a Sa: en amar a M por amor de IFGBS.

${ }^{261}$ bien se sigue Sa: bien se sigue que $\mathbf{M}$ bien se que IFGBS.
} 
hermano ${ }^{262}$ menor, la obiste falsado ${ }^{263}$ a la triste Breseyda. La qual, pues de ti non me plaze oyr ${ }^{264}$, commo sea la verdad en contrario, por esa razón tú menos lo debrías de mi conçebir. Miénbresete ${ }^{265}$ cómmo fue destruyda la noble çibdad de Belbesia, ${ }^{266}$ criança $^{267}$ de mi, e apartados de la humana vida mi antigua madre, marido, hermanos, más dignos de piedad que de pena, a los crueles manos de tus enemigos, en vista de los quales la sangre ${ }^{268}$ ynoçente reclama vengança, contrasta ${ }^{269}$ e refresca las en$\operatorname{tranas}^{270}$. De mi, pues, ¿a quál voluntad lo conçibe $\mathrm{o}^{271}$ naturaleza consiente que yo pueda bevir en amor de los que tanta ofensa ${ }^{272}$ me fizieron? Lo qual no se puede ven$\operatorname{gar}^{273}$ una sola muger cabtiba en poder de aquellos, parésçete ${ }^{274}$ que devo ${ }^{275}$ mostrar continençia de enemistad, o fengirles ${ }^{276}$ a mal e desear su vitoria, guardando los cuerpos $^{277}$ con buena esperança ¿Qué dizes ayrado, amador? ¿e non respondes? ¡Ay ${ }^{278}$ ! yo mezquina, yo agora ${ }^{279}$ pensaba razonarme contigo e non ser tan alexos ${ }^{280}$ de ti. ¡Tú, muy loada epístola, non respondes, mas por el hordenado ${ }^{281}$; desque ${ }^{282}$ feçiste la triste embaxada, luego ${ }^{283}$ en punto enmudeçiste. ¡O muda epístola, que más non fablas ${ }^{284}$ de una sola vez! Non dubdo yo, si el poder de la fabla a ti non fuese ${ }^{285}$ dado, que tú non juzgarías grand sabiduría saber yncobrir la enemistad donde no puedes fazer ${ }^{286}$ la vengança. De lo qual, si gloria e honor non reçibo segúnd ${ }^{287}$ justamente debría, non rezava corona deslealtad que te plaze ${ }^{288}$. E, Troylos, mejor mereçías segúnd ${ }^{289}$ por la

\footnotetext{
262 ser ermano Sa: su hermano MFGB segun su hermano IS.

263 la obiste falsado Sa M: la as falsado $\mathbf{S}$ la as falsada IFGB.

264 oyr commo sea la verdad, en contrario por esa razon tu menos lo debrias de mi conçebir Sa M: oyr non te plega de retractar IFGBS.

265 mienbresete Sa: mienbrate MIBS miembrete FG.

266 Belbesia Sa: Lernesia FGB Lernisa IS Lernesina M.

267 criança Sa IFGBS: criança y hechura M.

268 la sangre ynoçente Sa MS: la sangre de aquellos FGB la vista de aquellos I.

269 contrasta e Sa: contrista y $\mathbf{M}$ om. IFGBS.

270 las entrañas de mi Sa IFGBS: las mis entrañas M.

271 o Sa IFGBS: y M.

272 ofensa Sa IFGBS: de offensa M.

${ }^{273}$ no se puede vengar una sola muger cabtiva Sa: sy no puede vengar una sola muger cativa $\mathbf{M}$ si no venga (vengo FG) una (IS) sola muger cativa ISFGBS.

274 paresçete Sa IBS: parescere FG padeçere $\mathbf{M}$.

275 devo Sa: deva codd.

276 fengirles a mal Sa: fengirlos amar M fengir alegria IFGBS

277 cuerpos Sa: tiempos codd.

278 ay yo Sa: ay M o IFGBS.

279 yo agora pensaba Sa F: ya agora pensaba IGB yo agora me pensaba $\mathbf{M}$ ya agora razonar me pensaba $\mathbf{S}$.

280 alexos Sa M: lexos FGB lexana IS.

281 por el hordenado Sa: por el ordenador M por ordenança IFGBS.

282 desque Sa M: del que IGBS del quien F.

283 luego en punto Sa: luego codd.

${ }^{284}$ mas non fablas Sa M: non fablas mas IFGBS.

285 non fuese Sa: fuese codd.

286 fazer Sa IFGBS: aver M.

${ }^{287}$ segund justamente debria Sa: segund justamente devia M segund (segun IS segunt B) justiçia IFGBS.

288 plaze Sa: plaze a mi dar codd.

289 segund por la çeberte Sa: segun por la presente M segund por (por om. FG) la breve IFGBS.
} 
çeberte enseñaría, aviendo para lo dezir si bien ${ }^{290}$ te recuerdas del planto escavo ${ }^{291}$ autor e cosas pasadas ${ }^{292}$ por mi la noche que dezis. Del nuestro despido, e un ${ }^{293}$ agora, non se me olvidarán ${ }^{294}$ las grandes ${ }^{295}$ ynestançias e soplicaçiones que durante $1 a^{296}$ escura tiniebra por mi ofreçer ${ }^{297}$ a ti non çesavan. Las rodillas ${ }^{298}$ e piernas en tierra muy contristada delante ti, grand pena guardando: “¡Piedad ayas solas ${ }^{299}$ de mi, que la puedes aver, e más non te cuesta de solo querer ${ }^{300}$ ! Non vengas en tanta deslealtad e crueça que padescas yo ${ }^{301}$ viva solitaria de ti. Ssi que asaz $z^{302}$ poco $^{303}$ demando. Non digo trueques ${ }^{304}$ la sola soberana madre por la forestera amiga Ipodenía, que por mi dexes al magnífico padre, segúnd yo dexo $0^{305}$ el mío por ti, mas sola ${ }^{306}$ te pido por merced que non pierdas tu fama, ni pierdas tu sierva, el nonbre leal e ardid que posees no quieras trocar por el nonbre contrario. El qual non deseas ${ }^{307}$ aver quando una sola muger ${ }^{308}$ que dizes por ser ${ }^{309}$, reclamante su curso ${ }^{310}$ de ti, consentiste ${ }^{311}$ levar de tus enemigos, tú poderoso de le socorrer, presente seyendo e non le valer. Si el afamado ${ }^{312}$ Hércules, vençedor de la yra $^{313}$ e del brabo león en la selva Menia ${ }^{314}$, non ovieras $^{315}$ aquistado $^{316}$ mejor su amiga, el çenturio Meso oviese oy ${ }^{317}$, día viturioso $^{318}$ fijo d'Almeña ${ }^{319}$ non oviese gloria de su vencimiento, en los días alegres e no-

\footnotetext{
${ }^{290}$ si bien Sa: e aun sy bien $\mathbf{M}$ oosy bien $\mathbf{S}$ o, o, o e si bien I oy si bien FG oye si bien $\mathbf{B}$.

291 escavo Sa: esquivo codd.

292 cosas pasadas por mi la noche que dezis (dizes M) del nuestro despido (despedir M) Sa M: cosas pasadas del nuestro despido (dispidio I despidio $\mathbf{S}$ despedido B) IFGBS.

${ }^{293}$ un Sa: aun MFGB om. IS.

294 olvidaran Sa IS: olvidan MFGB.

295 grandes Sa M: om. IFGBS.

296 la Sa IFGBS: aquella M.

${ }^{297}$ por mi ofreçer a ti no çesavan (çesava M) Sa M: ofreçiendome a ti fazia non çesando IFGBS.

298 las rodillas e piernas en tierra muy contristada delante de ti grand pena guardando piedad Sa: las rodillas en tierra muy contristadas (contritada B) delante de ti a grand pena gridando piedat IFGS las rodillas pronas en tierra a grand pena gimiendo seyendo muy contristada delante de ti diziendo piedat $\mathbf{M}$.

299 solas Sa: sola M om. IFGBS.

${ }^{300}$ querer non vengas Sa M: querer deteniemdome a ti non vengas (venga FG) IFGBS.

301 yo Sa IFGBS: y M.

302 si que asaz Sa: asi que IFGBS se que $\mathbf{M}$.

303 poco demando Sa IFGBS: poco pido $\mathbf{M}$.

304 trueques Sa IFGBS: dexes M.

305 dexo Sa M: dexe IFGBS.

306 sola Sa M: solamente IFGBS.

307 deseas Sa IFGBS: descreas M.

308 muger Sa: amiga codd.

309 por ser Sa: poseer codd.

310 su curso Sa: socorro codd.

311 consentiste levar de tus enemigos Sa: consentiste levar en poder de aquellos IFGBS consientes levar M.

312 afamado Sa IFGBS: famoso M.

313 de la yra e del brabo leon Sa: de la yra del bravo leon $\mathbf{M}$ de la ydria (ydra S) del bravo leon IFGBS.

314 selva Menia Sa: selva venia IFGBS selvia Ydam M.

315 ovieras Sa: oviera M oviese IFGBS.

316 aquistado mejor Sa: conquistado mejor IS mejor conquistado (conquistada B) MFGHB

317 oy dia Sa IFGBS: oy M.

318 viturioso Sa M: virtuoso IFGBS.

319 d'Almeña Sa: Altimena M Almena S Almenia IFGB.
} 
ches plazibles que después ovo, oviese ${ }^{320}$ con Daymira; lo qual, sy a ti cayera ${ }^{321}$ en plazer, segúnd que a él al, domante yugo de fiel amor ${ }^{322}$, ygualmente vos ${ }^{323}$ apremiara". Por el grand poder que tenías, tú lo podieras bien desviar sin ningúnd ${ }^{324}$ título poder $\operatorname{contrastar}^{325}$. ¿Pues quál fue bien ${ }^{326}$ la causa ynfortunada? Yo ${ }^{327}$ non la sise escrebir nin condenar, a ti justamente condenar ${ }^{328}$, ynjusto de mi. Non digo que as mi desleal, segúnd dizes yo ser a ti, mas digo que tu condenado, antes quel nasçido, hermano, lançado a las fieras en la selva Ydo conoçido por desleal, que fue más costante a la fija de Leda, publicada por ynfiel, que tú fuyste a mi, desierta ${ }^{329}$ de aquesta manzilla. ¡E bien aventurada Elena, que tantas venidas de prinçipes veniste ${ }^{330}$ en solo ${ }^{331}$ de ti, e por solo contraste e defensa de Paris! Aún oy te çercan los muros de Troya, e non enbargante por aquesto $^{332}$ de ti falleçidos sean el valiente e glorioso Éstor ${ }^{333}$, rey de Protesalao, Morión, Meneón, Archílogo, Protenon e Ortaneo e Opon el gigante, rey de la Rista, e otros ynumerables reyes, e duques, condes, caualleros, altos señores e toda la gentile$\mathrm{za}^{334}$ e mançebía del universo, sola por ti perezca de cada un día. Non beo çesar al tu amador ser firme e costante en tu buen ${ }^{335}$ amor. Mas, jo sin ventura Breseyda!, que non fuyste bien demandada quando luego fueste otorgada, syn ninguna se adoleçiese yn memoria oviese de ti. E por cuya represa ${ }^{336}$ nueba me cae la guerra non començara, ca días abía que hera començada, nin se dexara continuar, pues que yo rendida, más todavía se esforçó. ¡O devían ${ }^{337}$ la probidençia de la provero ${ }^{338}$ la cabsa! ¡Absuelto ${ }^{339}$ poder de la alta espera! ¡Regnantes ${ }^{340}$ en la ursa del polo! Juno e Minerba, contrarias de

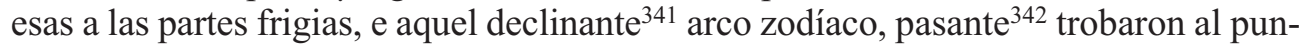

320 oviese Sa M: oviera IFGBS.
321 cayera Sa M: cayese IFGBS.
322 amor Sa MFGB: amador IS.
323 vos Sa IFGBS: te M.
324 ningund titulo Sa: ninguno codd.
325 poder contrastar Sa: te lo contrastar M te lo pudiera contradezir IFGBS.
326 bien la causa Sa: la causa codd.
327 yo non la sise escrebir Sa: yo non la (lo FG) oso escrivir IFGBS yo no lo oso dezir M.
328 condenar ynjusto Sa: injusto condenador codd.
329 desierta de aquesta manzanilla Sa $\mathbf{M}$ : om. IFGBS.
330 veniste Sa: viste venir IFGBS viste M.
331 en solo Sa: en sola demanda codd.
332 por aquesto de ti falleçidos sean $\mathbf{S a}$ M: por causa de ti fallesçido sea IFGBS.
333 Estor rey de Protesalao Morion Meneon Archilogo Prolenon e Ortaneo Opon el gigante rey de la Rista Sa: Ector rey Protesalao Omero Magno Archilego Protenor el gigante rey de Lorisa IFGBS Etor Protesalao Humenco Meneo Archilogo Protenor Ortamo Patruclon Upon el gigante el rey de la loriga $\mathbf{M}$.

334 la gentileza e mançebia Sa: la gentil mancebia IFGBS la señoria M.

335 buen amor Sa M: amor IFGBS.

${ }^{336}$ represa nueba me cae la guerra Sa: represa nuevamente la guerra codd.

337 o devian la probidençia Sa: o divinal providencia codd.

338 de la provero la cabsa Sa: primera causa IFGBS causa primera $\mathbf{M}$.

339 absuelto Sa: o assoluto codd.

340 regnantes en la ursa del polo Sa: o regnantes (regnares I reynares $\mathbf{S}$ ) en la hygosa del polo ( apolo B po-

blo $\mathbf{G}$ pueblo F) IFGBS o reynante en la yurza del polvo $\mathbf{M}$.

341 declinante Sa MI: declarante FGBS.

${ }^{342}$ pasante trobaron Sa: pasante calurio M passante color FG posante coloro B posant (oposante $\mathbf{S}$ ) coloro IS. 
to treta $^{343}$ seyco, padesçen qual demante marido su propria muger ${ }^{344}$ non deve ser otorgada, e la triste biuda al cruel matador suyo non deba ser denegada! ¡O ynfernales dioses Pruto ${ }^{345}$, e Minus e Redamantes, prínçipes de los nuebe çercos, poderosos en las firmas $^{346}$ e peñas ${ }^{347}$ de las ostiagias tenebrosas, e lançada ${ }^{348}$ del mundano çelestial regimiento a los nuestros soberanos diones June, Jobe, Saturno, Jenio ${ }^{349}$, Mercurio, Marteb ${ }^{350}$, Bulán ${ }^{351}$, Netuno, Sol ${ }^{352}$, Orto, Líbero ${ }^{353}$, yndignos ${ }^{354}$ de aquel Juezes de tanta desigualdad! O tú, la cabsa de mi ynfortuno ${ }^{355}$ término de la grand universidad mía: ¿el quál viento se fizo ${ }^{356}$ boreas, austral volvió las alas del tu coraçón a pensar de mi el pensamiento contrario? E non pienses que di al olvido ${ }^{357}$ el día de la honzena ${ }^{358}$ vatalla, quando en vitoria de tus enemigos quinientas nabes e más las brausaste ${ }^{359}$, el canpo e las tiendas robaste de aquellos, mas non beniste en robo de mi que, vista la rota $^{360}$ con prestos los cargó de todas mis joyas, arreos ${ }^{361}$, jaez e aferes ${ }^{362}$, esperava quándo vernías voluntarioso para me llevar; ¡más quisiste venir en despojo de la rica presa que de la esperante amiga Ypodonía!. ¡O amante ${ }^{363}$ felidades, tu querella del tardante $^{364}$ Ejeo, dios del mar fijo de la Ninfa e de Teseo, non venido ${ }^{365}$ el tienpo por tí esperado, forçado de la grand tormenta ${ }^{366}$ contrariedad de los vientos levantes en coso ${ }^{367}$ de las singulantes ${ }^{368}$ velas, de largo corrientes de los altos ${ }^{369}$ mares! E no oviste ra-

\footnotetext{
343 treta seyco Sa: terçelario $\mathbf{M}$ tratarico (tracarico F) IFGBS.

${ }^{344}$ muger non deve ser otorgada. E la triste biuda al cruel matador suyo non deba ser denegada Sa M: muger (mugier I) le sea negada IFGBS.

345 Pruto e Minus e Redamantes prinçipes Sa: Plato e Domus e Radiarco prinçipes IFGBS Pluton Minus radiantes prinçipes $\mathbf{M}$.

346 firmas Sa: furias codd.

${ }^{347}$ peñas de las ostiagias tenebrosas Sa: penas estigias tenebrosas IFGBS penas de las escuras tiniebras M.

348 lançada Sa: lançad MIBS lançando F lançant G.

349 Jenio Sa: Gano (Jano F) IFGBS Geminis M.

${ }^{350}$ Marteb Sa: Marte IFGBS om. M.

351 Bulan Sa: Bulcan FG Vulcan IBS Vulcano M.

352 Sol Orto Sa: Solarco IBS om. FG Solorto M.

353 Libero Sa IBS: Binero M om. FG.

354 yndignos de aquel juez Sa IBS: justos de aquel juez M om. FG.

355 de mi ynfortuno termino Sa: del muy infortunado termino IFGBS de mi infortunio termino $\mathbf{M}$

356 el qual viento se fizo boreas austral Sa: el qual viento (fue el viento FGB) saphiro (sophiro GB sufrio IS) boreas austral IFGBS e qual viento boreas zefiro austral $\mathbf{M}$.

${ }^{357}$ di al olvido Sa: de a olvido FGB dexo (dex S) olvidado IS aya olvidado $\mathbf{M}$.

358 honzena Sa: dezena ( $\left.\mathrm{x}^{\mathrm{a}} \mathbf{F}\right)$ IFGBS decima quarta $\mathbf{M}$.

359 brausaste Sa: brusaste IS abrusaste GB quemaste MF.

${ }^{360}$ la rota con prestos los cargo (cargos M) Sa M: la rota (ropa $\left.\mathbf{S}\right)$ compuesta con los cargos (argos B carros S) IFGBS.

361 arreos Sa M: arreo (areo S) IBS arree FG.

362 jaez e aferes esperava Sa: jaezes de toda mi casa esperava IFGBS jaezes afferes esperando M.

363 o amante felidades tu querella Sa: o amante Fedra das tu querella codd.

364 del tardante Ejeo Sa: del tardante nieto de Egeo M del retraymiento de egeo (ageo IS) IFGBS.

365 venido Sa M: veniendo IFGBS.

366 tormenta contrariedad Sa: tormenta e contrariedad IFGBS tormenta del mar por contrariedad $\mathbf{M}$.

367 en coso de las $\mathbf{S a}$ : en cossolas GB en cuesolas $\mathbf{S}$ en cossola $\mathbf{F}$ en solas MI.

368 singulantes velas Sa: semblantes velas IFGBS sensulares velas M.

369 los altos mares Sa MFGB: las mares IS.
} 
zón de te querellar $\mathrm{a}^{370}$ conparaçión de la triste Breseyda, ni te dar a la sentible muerte que, por so la tardança e soledad ${ }^{371}$ de aquel, solitaria prendiste ${ }^{372}$ en la grand esquividad $^{373}$ del desierto. E si por ventura las nabes entraran los puertos ${ }^{374}$ de Ródope, e el capitán de aquellas non veniera en demanda ni en vista ${ }^{375}$ de ti, e levara en un punto las anclas ${ }^{376}$ faziendo la vía contraria, a la hora podieras tú bien dezir: «Falleçida es la fe e la buena esperança», e dar de tí el mal cabo que diste; mas non por la vía que te a ello mobiste, e faziendo él todo su deber por llegar a las sus riberas, e la grand fortuna le seyendo contraria, e después armando ${ }^{377}$ a los flumigos ${ }^{378}$ de sitio, entendido el doloroso fin de tus días, non tardar ${ }^{379}$ con mucha tristeza abraçarse con el tronco ${ }^{380}$ del árbol seco, por admiraçión de los nuestros dioses ${ }^{381}$ dado el espíritu, fuyste ${ }^{382}$ conbertida $^{383}$, el qual, luego en punto reberdeçió demostrando en sus verdes fojas ser de aquella naturaleza de árboles que almendros ${ }^{384}$ dizen en las partes ${ }^{385}$ de acá, los quales antes del tienpo pierden ${ }^{386}$ sus fojas, segúnd que tú, filida ${ }^{387}$, la firme esperança. Non dirán así de la sin ventura de mi, que antes de tienpo ${ }^{388}$ yo aya perdido la mía, e commo el tiempo esperado ya sea pasado e venido aquel que mejor me fuera non ser venido. El qual vino, mas no por mi, a las tiendas, mas no a la mía; e más quiso robar el pavellón valioso ${ }^{389}$ del muerto Palamides que levar ${ }^{390}$ en su presionar, quien ${ }^{391}$ luengos tienpos fue carçelera de su coraçón ¡O desamada ${ }^{392}$ e amante Ypodomía, venida en tanto desprecio al tu amador, que las arreadas ${ }^{393}$ cosas le fueron más ${ }^{394}$ caras e ama-

\footnotetext{
370 a Sa M: en IFGBS.

371 e soledad Sa M: om. IFGBS.

372 solitaria prendiste $\mathbf{S a}$ M: solitario por ti (puerto $\mathbf{F}$ porte $\mathbf{G}$ te $\mathbf{B}$ ) diste IFGBS.

373 esquividad Sa IFGBS: escuridat $\mathbf{M}$.

374 los puertos de Rodope (Redope M) Sa M: el puerto de Rodope (Rodopo FG Redope S Redrope I) IFGBS.

375 ni en vista $\mathbf{S a}$ : ni vista $\mathbf{M}$ e en vista $\mathbf{I F G B}$ e vista $\mathbf{S}$.

376 las anclas Sa M: las ancoras (anchoras F) IFGBS.

377 armando Sa: arribando codd.

378 flumigos de sitio $\mathbf{S a}$ : flumarias (flumares $\mathbf{S}$ flumarias $\mathbf{G}$ flamayras F) de Xanto (Xanco IB Sanxo G Xaço
}

S) IFGBS flumarias de sytio $\mathbf{M}$.

379 no tardar Sa M: no tardando IFGBS.

380 con el tronco del arbol seco Sa M: con el arbol (arbor G) del tronco seco IFGBS.

381 dioses Sa IFGBS: dias M.

382 fuyste Sa: fue codd.

383 conbertida Sa: convertido codd.

384 almendros Sa MFGB: almendras I almendros $\mathbf{S}$ a.c. almendras $\mathbf{S}$ p.c.

385 en las partes de aca $\mathbf{S a}$ : en las partidas de aca $\mathbf{M}$ en las partes de Asia IFGBS.

386 pierden sus fojas Sa: pierden sus flores M floreçen e pierden sus flores IFGBS.

387 que tu filida la firme Sa: que te era fallida la firme M que tu Fedra (Fedra om. F) la firme IFGBS.

388 de tienpo yo (yo om. M) aya perdido la mia. E commo el tienpo esperado ya (ya om. M) sea pasado Sa

M: de tiempo esperando (esperado $\mathbf{S}$ ) commo ya sea pasado IFGBS.

${ }^{389}$ valioso Sa M: valeroso IFGBS.

${ }^{390}$ que levar en su presionar Sa: que levarme por su prisionera M que (e FG) prisionar IFGBS.

${ }^{391}$ quien luengos tienpos fue carçelera Sa: la que luengos tienpos fue carçelera IFGBS aunque fuy largos tiempos carçelera $\mathbf{M}$.

392 desamada Sa MGB: desamanda F demasiada IS.

393 arreadas Sa: apreçiadas FGB apartadas IS preçiosas M.

${ }^{394}$ mas caras e amadas de ti si Sa: mas caras e amadas si IFGBS mas karas que tu sy $\mathbf{M}$. 
das de ti! Si mobido por abariçia, sienpre enemiga te conoçió, e non devieras por otro dexar la mi tienda, a la qual en valía ${ }^{395}$ ninguna de Greçia se podía ygualar; nin a ti se escondía el grand thesoro e aver de mi padre, e yo ser la más arreada de las muy generosas damas de Frigia; si por solo pavor, que en tu coraçón nunca pudo ${ }^{396}$ alojar, pues vençedor heres, a tu sabiaçión ${ }^{397}$ me podieras ; mas aquella lealtad e firmeza que mobieron a ti consentir en el mi destierro, te fezieron retraher del alcanço. Ya non ${ }^{398}$ te plazía venir ${ }^{399}$ e por levarme que saberte ploguiese de mi, ya venieras desconfiarme ${ }^{400}$ e por que yo nuebas sopiera de ti e solamente dixieras: “¿mueres ${ }^{401}$ o vives, catiba muger de Lenesia ${ }^{402}$ ? Si vives, vive, que yo vida fago.» Mas a quien denegabas la vista, non veo cómmo otorgases la fabla. Bien puede ${ }^{403}$ dezir los nuestros coronados poetas so la verde yedra ${ }^{404}$, non aver seydo tan ocupados en perpetual $^{405}$ por su escritura las fazañas de los tus amores, que por bien amar a te dar a mi cometiste, commo fueron estoria el peligroso paso quel leal amador Leandro, regnante la madre de los crueles ${ }^{406}$ tres Furios pasó vegadas ${ }^{407}$ sin cuento por se dar a Oro $^{408}$, su bien ${ }^{409}$ que esta señor, nadando por las brabas hondas de la esquiba ${ }^{410}$ mar avideaba ${ }^{411}$, tallando con las serenas ${ }^{412}$, golfines sollantes, peçes e belfas ${ }^{413}$ marinas, llamando el sabor de Diana, Eolo ${ }^{414}$, dios de los vientos, Saliçia ${ }^{415}$, muger de Netuno, e Venillia ${ }^{416}$ deesas del mar, fasta $\operatorname{arribar}^{417}$ al çercado ${ }^{418}$ noble de sus palaçios, donde en bista sola de aquella luego en punto recobrava sus fuerças, e los grandes fríos vençidos fuýan ${ }^{419}$ de la calor ${ }^{420}$ natural, en grand reposo deseada fol-

\footnotetext{
395 en valia ninguna de Greçia se podía (puede M) ygualar Sa M: ninguna en aver (en aver ninguna IS) se podia (pudiera $\mathbf{S}$ ) ygualar IFGBS.

${ }^{396}$ pudo alojar Sa: alojar pudo IFGBS pudo entrar M.

397 sabiaçion Sa: salvaçion M salvo IFGBS.

398 ya non Sa IFGBS: e ya que no $\mathbf{M}$.

399 venir e por levarme Sa: venir por me levar codd.

400 desconfiarme Sa IFGBS: syquiera a desfiuzarme M.

401 mueres o vives Sa M: bives o mueres IFGBS.

402 de Lenesia Sa: de Lernesia FGB de Lernisa IS de Lernesyna M.

${ }^{403}$ puede dezir Sa: pueden dezir codd.

404 yedra Sa IFGBS: yerva M.

405 perpetual Sa FG: perpetuar MIBS.

406 de los crueles tres Furios Sa: de las crueles tres Furias IFGBS de los volubles amores M.

407 vegadas Sa M: vezes IFGBS.

408 Oro Sa: Ero FGB Ereo IS Hero M.

409 bien que esta señor $\mathbf{S a}$ : su bien quista (questa $\mathbf{G}$ aquesta $\mathbf{F}$ ) señora $\mathbf{c o d d}$.

410 de la esquiba mar Sa IS: del esquivo mar MFGB.

411 avide abatallando $\mathbf{S a}$ : avida (avido $\mathbf{B}$ havida $\mathbf{F}$ ) batalla IFGB aviendo batalla $\mathbf{S}$ batallando $\mathbf{M}$.

412 serenas golfines Sa IFGB: sirenas y gulfines $\mathbf{S}$ serenas y dalfynes $\mathbf{M}$.

413 belfas marinas Sa M: bestias (vestias FG) marinas IFGBS.

${ }^{414}$ Eolo dios de los vientos Sa: Yolo (Eyolo I) dios de (de om. I) los vientos IFGBS e Boreas de los vientos M.

415 Saliçia Sa M: Salçide IFGBS.

416 Venillia Sa: Vinilia M Venibla IFG Vinyella S Venbla B.

${ }^{417}$ arribar Sa: llegar codd.

418 çercado noble Sa: çercano molle $\mathbf{M}$ çercano muro IBS çercados muros $\mathbf{F}$ cercado muros $\mathbf{G}$.

419 fuyan Sa IFGBS: fuyen $\mathbf{M}$.

${ }^{420}$ calor natural Sa M: natural calor IFGBS.
} 
gança de sus trabajos; a los quales en muy más mayores non dubdes por ti me ovie$\operatorname{ses}^{421}$ ofreçido si Breseyda fuese otra Pantasilea, commo, Troylos ${ }^{422}$, heres el segundo Étor. ¡E si ${ }^{423}$ bien sopieses quantas vegadas ${ }^{424}$ por me dar a ti engaño la noche e desdigo las velas e guardas del canpo, e sola me toma el gallo cantante, llamando a la puerta Dardania que fallo cerrada, e ningúnd troyano me quiere abrir por que falleçida de mi pensamiento, maldiziendo ventura ${ }^{425}$, es por fuerça de me retraer e, retrayda, me dar a la secreta contenplaçión, a ${ }^{426}$ la qual me toma el sueño, en toda la noche non me parto de ti sienpre querría ${ }^{427}$ que durase! Desplázeme quando viene el día, e $\operatorname{tiran}^{428}$ e comiençan a abrir las finiestras de la oriental casa, e tiende ${ }^{429} \mathrm{su}$ vista a los montes Crineos $^{430}$, consagrados al alto Polo, ca fallo a la hora alongada de ti e de los sueños muy engañada. E yo, recordando bañada en lágrimas de coytas aviendo enojos pasando ${ }^{431}$, en otorgando la creençia, oras denegando segúnd me traýan los primeros motos ${ }^{432}$, después del estribo ${ }^{433}$ e doloroso llanto, toda de negro me luego vestí. Si dolor ${ }^{434}$ e cuydado ${ }^{435}$ se parte de mi, ya lo dexo aquí de escrevir por non te enojar por luenga ${ }^{436}$ epístola. La qual, si más ${ }^{437}$ larga verás que la tuya, non te maravilles, commo sea mayor la querella. Vesa por mí las manos a los muy esclareçidos rey Príamo e reyna Ecuba, tus progenitores ${ }^{438}$, e a tus hermanos ${ }^{439}$ Paris, e Eleno, e a la sabia Casandra, e Poliçena ${ }^{440}$, e Creusa e griega Elena. E reparte ${ }^{441}$ por mí las saludes ¡ay ${ }^{42}$ ! e non dexes por saludar a la triste Andrómaca e al gracioso ${ }^{443}$ niño Astrincas ${ }^{44}$, fijo de Yenta ${ }^{445}$. E ruego a los nuestros soberanos dioses que le quie-

\footnotetext{
${ }^{421}$ ovieses Sa: ovieras $\mathbf{M}$ oviese IBS oviesse $\mathbf{G}$ hoviesse $\mathbf{F}$.

422 Troylos Sa M: Troylo IS Troyllo FGB .

423 e si bien Sa: ay, ay, ay e si bien I, ay ay e si bien FGB ay ay ay sy bien $\mathbf{S}$ ay que sy bien $\mathbf{M}$.

424 vegadas Sa MIS: vezes FGB.

425 ventura Sa IFGBS: mi ventura $\mathbf{M}$.

426 a la qual Sa: en la qual IFGBS en lo qual $\mathbf{M}$.

${ }^{427}$ querría Sa IFGBS: queria M.

428 e tiran e comiençan Sa: e Tytan comiença codd.

429 tiende Sa IFGBS: estiende M.

${ }^{430}$ Crineos Sa: Crinedes M Cretos IFGBS.

431 pasando en otorgando Sa: pasando otorgando IFGBS passando M.

432 motos Sa: motus M motivos IFGBS.

433 estribo Sa: esquivo codd.

434 dolor Sa IFGBS: tristor M.

435 e cuydado se parte de mi ya lo dexo aqui de escrivir Sa: y deseo me acompaña (acompañava $\mathbf{S}$ acompañan B) yo lo dexo aqui escrevir IFGBS y desseo un solo momento se parte de mi, hago testigo a mi corazón, lo qual ya aqui dexo de escrevir $\mathbf{M}$.

436 luenga Sa MS: larga IFGB.

${ }^{437}$ mas larga veras Sa $\mathbf{M}$ : mas vieres IFB mas vieras $\mathbf{G}$ mayor vieres.

438 progenitores Sa IFGS: progenitos MB.

439 a tus hermanos Paris e Eleno Sa M: a tu hermano Paris IFGBS.

${ }^{440}$ Poliçena e Creusa Sa IFGBS: Poliçena M.

441 reparte Sa M: repite IFGBS.

442 ay e non dexes Sa: ay non dexes IS e non dexes MFGB

443 al gracioso niño Sa M: al su fijo IFGBS.

444 Astrincas Sa: Anastianes MF Anastranes G Anasties B Astianes IS.

445 de Yenta Sa: de Etor codd.
} 
ran guardar, e prosperar ${ }^{446}$ e longar la vida, en devida vengança del falleçido padre. E tú, la esperança nuestra, firme tu coluna del alto Ylión, solo anparo de los muros de Troya, esfuérçate ${ }^{447}$ en amor ${ }^{448}$ e en menbrança de mi, quebrantando la fe a los sueños, e muestra fuerças por me recobrar, e desfaçión ${ }^{449}$ e astrago ${ }^{450}$ de tus enemigos. E de las saludes, pues a Troylos eres reparador ${ }^{451}$, faz que non restes con la menor parte ${ }^{452}$. Del Siçio troyano con mucha tristura ${ }^{453}$, al segundo día a la hora octaba después de la dézima e quarta batalla.

\section{REFERENCIAS BIBLIOGRÁFICAS}

Avenoza, G. (2003), «Algunos libros de la biblioteca de Lope García de Salazar», Revista de Filología Española, 83, 1- 2, 5- 37.

AvenozA, G. (2006), «Lope García de Salazar: La formación de un bibliófilo y de su biblioteca, una visión general», eHumanista, 6, 34- 67.

Bravo, F. (2000), «Arte de enseñar, arte de contar. En torno al exemplum medieval», en $L a$ enseñanza en la Edad Media (X Semana de Estudios Medievales, Nájera, 1999), Logroño, Instituto de Estudios Riojanos, 303- 327.

Marín SÁnchez, A. Ma (1999), Lope García de Salazar. Istoria de las bienandanzas e fortunas, http:// parnaseo.uv.es/ Lemir/ Textos/ bienandanzas/ Menu.htm/ (Memoria de Licenciatura).

Marín SÁnchez, A. Ma (1995), «Otra fuente de las Bienandanzas e Fortunas de Lope de Salazar: las epístolas de Troilo y Briseida de Rodríguez del Padrón», en Medievo y Literatura. Actas del V Congreso de la Asociación Hispánica de Literatura Medieval, vol. III, Juan Paredes (ed.), Granada, 193- 211.

Rodríguez Herrero, A. (1967), Lope García de Salazar, Las bienandanzas e fortunas. Códice del XV. Primera impresión del texto completo, con prólogo, notas e indices. Introducción por el Excmo. Sr. Marqués de Arriluce de Ybarra, Bilbao.

Rogers, F. M., (1962), Gómez de Santiesteban, Libro del Infante don Pedro de Portugal, Lisboa, Fundaçao Calouste Gulbenkian, 1962

Saquero SuÁrez-Somonte, P.- GonzÁlez Rolán, T. editores (2010), Juan Rodríguez del Padrón. Bursario, Alcalá de Henares, Centro de Estudios cervantinos.

Severin, Dorothy Sh., -Sharrer, Harvey L. (1979), «Fifteenth- Century Spanish Fragments of a Lost Prose Alexander», Medium Aevum, 48, 2 , 205-212.

\footnotetext{
446 longar Sa: prolongar (om. F) codd.

447 esfuerçate Sa M: esfuerça IFGBS.

${ }^{448}$ En amor e en (en om. M) membrança de mi quebrantando la fe a los sueños e muestra (demuestra $\mathbf{M}$ ) Sa M: om. IFGBS.

449 desfaçion Sa M: despreçio IFGBS.

450 astrago Sa FG: estrago MIBS.

${ }^{451}$ Reparador Sa: repartidor MIBS repetidor FG.

452 parte del Siçio troyano Sa: parte el segundo troyano IFGBS parte de sitio griego M.

453 tristura al segundo día a la hora octaba después de Sa: tritura al segundo dia la ora oculta despues de IFGBS tristura a la octava despues de $\mathbf{M}$.
} 
SHARRER, Harvey L. (1977), «Evidence of Fifteenth Century Libro del Infante don Pedro de Portugal and its relationship to the Alexander Cycle», Journal of Hispanic Philology, 1, $2,85-98$.

SHARRER, Harvey L. (1979), The Legendary History of Britain in Lope García de Salazar 's Libro de las Bienandanzas e Fortunas, Philadelphia, University of Pensylvania Press.

Villacorta Macho, Ma C. (2005), Edición crítica del Libro de las buenas andanças e fortunas que fizo Lope García de Salazar (títulos de los libros XIII, XVIII, XX, XXI, XXIV y $X X V)$, Bilbao, Universidad del País Vasco. 